Article

\title{
Synthesis and Characterization of New Schiff Base/Thiol-Functionalized Mesoporous Silica: An Efficient Sorbent for the Removal of Pb(II) from Aqueous Solutions
}

\author{
Moawia O. Ahmed *(D), Ameen Shrpip and Muhammad Mansoor \\ Chemistry Department, College of Science, Taibah University, P.O. Box 30003, Al Madinah Al Munawarah 41477, \\ Saudi Arabia; shrpip@hotmail.com (A.S.); mansoorishaque@hotmail.com (M.M.) \\ * Correspondence: moahmed@taibahu.edu.sa; Tel.: +966-5655-48322
}

Received: 25 January 2020; Accepted: 18 February 2020; Published: 21 February 2020

check for updates

\begin{abstract}
A new type of silica hybrid material functionalized with Schiff base-propyl-thiol and propyl-thiol groups (adsorbents $\mathbf{1}$ and 2, respectively) was synthesized using a co-condensation method. The synthesized materials and their starting materials were successfully characterized using a variety of techniques such as Fourier transform infrared spectroscopy (FTIR), scanning electron microscopy (SEM), X-ray diffraction (XRD), nitrogen adsorption-desorption isotherms, the Brunauer-Emmett-Teller (BET) surface area calculation method, the Barrett, Joyner, and Halenda $(\mathrm{BJH})$ pore size calculation method, thermogravimetry analysis (TGA), and $1 \mathrm{H}$ and $13 \mathrm{C}$ nuclear magnetic resonance (NMR) spectra. The results indicate that the new material (adsorbent 1 ) has a large surface and possesses different functional groups $(-\mathrm{SH},-\mathrm{OH},-\mathrm{C}=\mathrm{O}$ and $-\mathrm{N}=\mathrm{C})$. The newly synthesized hybrid materials ( $\mathbf{1}$ and $\mathbf{2}$ ) were investigated as potential adsorbents for removal of toxic heavy metals, such as $\mathrm{Pb}$ (II) from aqueous solutions. The adsorption results show that materials 1 and $\mathbf{2}$ have different sorption properties and were found to be effective adsorbents for $\mathrm{Pb}$ (II) removal from aqueous solutions. In addition, compound 1 exhibited a higher adsorption capacity for $\mathrm{Pb}$ (II) compared to compound 2. The results showed that the optimum $\mathrm{pH}$ for $\mathrm{Pb}$ (II) sorption was 6.5. Contact time was observed to occur after $30 \mathrm{~min}$ for $25 \mathrm{mg} \mathrm{L}^{-1} \mathrm{~Pb}(\mathrm{II})$ concentration and adsorbent dose of $0.4 \mathrm{~g} \mathrm{~L}^{-1}$ at $25^{\circ} \mathrm{C}$.
\end{abstract}

Keywords: heavy metals; hybrid materials; functionalized; Schiff base; lead; Langmuir and Freundlich

\section{Introduction}

Excessive heavy metal concentrations in drinking water pose significant threats to human health and the environment. For example, lead $(\mathrm{Pb})$ is a very commonly used metal with a relatively high atomic mass, atomic number, and density of $11.34 \mathrm{~g} / \mathrm{cm}^{3}$. $\mathrm{Pb}$ is widely used in battery production, paints, and fertilizers. However, exposure to high $\mathrm{Pb}$ levels can cause major problems in the biosynthesis of hemoglobin $(\mathrm{Hb})$, which is important for oxygen transport in humans and other vertebrates. In addition, $\mathrm{Pb}$ can cause serious damage to the liver, kidneys, and nervous system. Elimination of highly toxic heavy metal ions, such as $\mathrm{Pb}$, mercury $(\mathrm{Hg})$, chromium $(\mathrm{Cr})$, copper $(\mathrm{Cu})$, cobalt $(\mathrm{Co})$, and zinc $(\mathrm{Zn})$, from water is necessary and recently has been the subject of extensive research. Polluted water can cause serious environmental problems and can cause harm to both humans and other animal life [1-4].

A number of techniques are used for treatment of wastewater discharge. Some of the primary methods include precipitation, flocculation, flotation, and chelation reactions. Other methods include ion-exchange columns, solvent extraction, reverse osmosis, and electrolytic plating on an anode. Nonetheless, these methods suffer from being costly and inappropriate for removing a lot of 
contaminants; for instance, large amounts of chemicals are needed for lime precipitation, and its electrolytic recovery suffers from corrosion [5-13]. Recently, low-cost adsorbents derived from functionalized inorganic-organic hybrid materials have been extensively used as adsorbents for removal of heavy metal from wastewater because of their notable properties, such as strong binding affinities and high adsorption capacities towards heavy metal ions; in addition, they have large surface areas and good chemical, thermal, and mechanical stabilities [14-24].

Among the different types of adsorbents is mesoporous silica material, which is widely used and a well-known adsorbent for removal of toxic heavy metals. This material consists of a porous structure, and there are two types: (1) hexagonal (MCM-41), which is a silica-based mesoporous material with size between 50 and $120 \mathrm{~nm}$, with different morphologies and hollow and core-shell spheres and (2) three-dimensional cube (MCM-48), which has four different structures (worm-like, helical, radial, and lamellar). MCM-41 has been extensively used in different applications, such as catalysis, adsorption, and separation processes, and as drug carriers [25]. Recently, modifications of MCM-41 with organic compounds in order to enhance the properties of MCM-41 and to improve its adsorption capacities towards toxic heavy metals has attracted more interest [26-29]. For example, Liu and co-workers [30] prepared novel zwitterion hybrid polymer adsorbents for adsorption of $\mathrm{Pb}$ (II) and $\mathrm{Cu}$ (II) ions from aqueous solution. Pavan et al. [31] prepared a stable mesoporous aniline/silica sorbent material for adsorption of $\mathrm{Co}, \mathrm{Zn}$, and cadmium chlorides $\left(\mathrm{CoCl}_{2}, \mathrm{ZnCl}_{2}\right.$, and $\mathrm{CdCl}_{2}$, respectively) from aqueous and ethanol solutions.

On the other hand, the stable azomethine group (-C=N-R, in which $\mathrm{R}$ is either an alkyl or aryl), also known as an imine or Schiff base, has been shown to play an important role in stabilizing metal complexes because it can act as a good binding site for many transition metals and therefore can form stable coordination complexes. Recent studies have demonstrated that mesoporous silica materials (MCM-41) can be immobilized with organic groups such as thiols, anilines, and Schiff bases and then used successfully for removal of toxic heavy metals from contaminated water. For example, Radi et al. [32] anchored a Schiff-base on silica gel for adsorption of Cd(II), Cu(II), and Zn(II) from aqueous solutions. The author concluded that the adsorbent can be regenerated and used several times without loss of its activity. However, the disadvantage of their adsorbent was the maximum sorption of $\mathrm{Cu}$ (II), $\mathrm{Zn}(\mathrm{II})$, and $\mathrm{Cd}(\mathrm{II})$ occurred at a $\mathrm{pH}$ of $>8$. Therefore, at this $\mathrm{pH}$, hydrolysis of these metal ions may occur, and this hydrolysis makes it difficult to distinguish between hydrolyzed and adsorbed metals.

The goal of this present study was to prepare new modified mesoporous silica materials as adsorbents with large surface areas, regular pores, and high adsorption capacities for removal of toxic heavy metal ions from contaminated water. For this purpose, we have fabricated two hybrid materials, namely, Schiff base-modified and propyl-thiol-modified silicas (adsorbents $\mathbf{1}$ and 2, respectively) by a direct co-condensation method using (3-mercaptopropyl) trimethoxysilane as the silica source. The removal of heavy metal ions such as $\mathrm{Pb}(\mathrm{II})$ from aqueous solutions by adsorbents $\mathbf{1}$ and 2 was examined by considering the effect of different factors, such as $\mathrm{pH}$ and contact time, between the absorbent and surrounding solution.

\section{Materials and Methods (Experimental Section)}

\subsection{Materials}

2-amino-4,5-dimethoxybenzoic acid, 4-hydroxybenzaldehyde, (3-mercaptopropyl) trimethoxysilane, and the $1000 \mathrm{mg} / \mathrm{L}$ standard solution with $\mathrm{Pb}$ (II) were purchased from Sigma Aldrich and used without modifications. $\mathrm{HCl} 0.5 \mathrm{M}$ and $\mathrm{NaOH} 0.5 \mathrm{M}$ were used to adjust the required $\mathrm{pH}$. All reagents and solvents (analytical grade) were used without any further purification. All solutions were prepared with fresh deionized water obtained from a Milli-Q water system. 


\subsection{Instrumentation}

The residual $\mathrm{Pb}$ (II) concentration was determined by inductively coupled plasma mass spectrometry (ICP-MS; Agilent 7500). A digital pH meter was used to determine the $\mathrm{pH}$ of water samples. Fourier-transform infrared (FTIR) spectra were obtained with a Perkin Elmer System 2000. Scanning electron microscopy (SEM) images were obtained on an FEI-Quanta 200. The ${ }^{1} \mathrm{H}$ and ${ }^{13} \mathrm{C}$ nuclear magnetic resonance (NMR) spectra of the Schiff base were obtained with a CP MAX CXP 300 MHz. A specific area of modified silica was determined by using the Brunauer-Emmett-Teller (BET) equation. Nitrogen adsorption-desorption was obtained by means of a Thermoquest Sorpsomatic 1990 analyzer after the material had been purged in a stream of dry nitrogen. Thermal gravimetric analysis (TGA) was conducted on a SDT Q 600 analyzer. Powder X-ray diffraction (XRD) patterns for determining phase purity and structure of the end product were performed on an XRD P-6000-Shimadzu $X$-ray diffractometer $(40 \mathrm{kV} / 20 \mathrm{~mA})$ using a conventional $\theta-2 \theta$ reflection geometry and $\mathrm{Cu} \mathrm{K} \alpha$ radiation $\left(\lambda=1.5406 \mathrm{~A}^{\circ}\right)$.

\subsection{Preparation of the Schiff Base 2-(4-Hydroxybenzylideneamino)-4,5-Dimethoxybenzoic Acid}

2-amino-4,5-dimethoxybenzoic acid $(1 \mathrm{mmol})$ and 4-hydroxybenzaldehyde $(1 \mathrm{mmol})$ were mixed and heated to reflux for $4 \mathrm{~h}$ in ethanol $(40 \mathrm{~mL})$. The orange precipitate of the Schiff base was filtered, washed with cooled ethanol, and dried. The yield was $80 \%$ (Scheme 1). Analytical conditions were set for several different methods: (1) FTIR $\left(\mathrm{KBr}, \mathrm{cm}^{-1}\right)$ : 1521 ( $(\mathrm{C}=\mathrm{N}$ Schiff base), $1601(\nu \mathrm{C}=\mathrm{O}), 1452-1354$ $(v \mathrm{C}=\mathrm{C}), 3442$ phenolic hydroxide $v(\mathrm{OH}) ;(2)$ 1HNMR (DMSO, ppm, $400 \mathrm{MHz}): 3.62(\mathrm{~s} 3 \mathrm{H}), 3.72(\mathrm{~s}, 3 \mathrm{H})$, $6.32(\mathrm{~s} \mathrm{H}), 6.91-0.6 .93(\mathrm{~d}, 2 \mathrm{H}), 712(\mathrm{~s}, \mathrm{H}), 7.75-7.77(\mathrm{~d}, 2 \mathrm{H})$ and $9.78(\mathrm{~s}, \mathrm{H})$; and (3) 13C NMR (dimethyl sulphoxide, DMSO, ppm, $400 \mathrm{MHz}): 55.64,55.38,99.49,101.05,113.59,116.31(2 \mathrm{C}), 128.84,132.61(2 \mathrm{C})$, $139.55,148.71,154.94,163.80,169.62$, and 191.50.<smiles>COc1cc([NH3+])c(C(=O)O)cc1C</smiles><smiles>O=Cc1ccc(O)cc1</smiles>



\section{Schiff base}

Scheme 1. Schiff base synthesis.

\subsection{Preparation of Schiff Base-Thiol Silica (Adsorbent 1)}

The Schiff base 2-(4-hydroxybenzylideneamino)-4,5-dimethoxybenzoic acid) (3) (first reaction) was added to a solution of deionized water/EtOH $(25.0 \mathrm{~mL}, 50 \% \mathrm{v} / \mathrm{v})$. The resulting suspension was stirred for $30 \mathrm{~min}$. To this suspension, 3-(triethoxysilyl) propane-1-thiol (two equivalents) in deionized water/EtOH $(25.0 \mathrm{~mL}, 50 \% \mathrm{v} / \mathrm{v})$ was added. A few drops of base were added as catalyst. The mixture was stirred for $72 \mathrm{~h}$ at $60^{\circ} \mathrm{C}$. The resulting yellowish solid (adsorbent 1 ) was filtered and washed several times with distilled water and ethanol. The solid was then dried under vacuum overnight at $105^{\circ} \mathrm{C}$ before characterization (Scheme 2).

The propyl-thiol functionalized silica material (adsorbent 2) was prepared by the sol-gel method (direct synthesis) after stirring (3-mercaptopropyl) trimethoxysilane in an ethanol/water mixture (50\% $v / v$ ) using base as catalyst (Scheme 3). The mixture was stirred for $72 \mathrm{~h}$ at $60^{\circ} \mathrm{C}$. The resulting white solid was filtered and washed several times with distilled water and ethanol. The solid was then dried under vacuum overnight at $105^{\circ} \mathrm{C}$ (Scheme 3). 

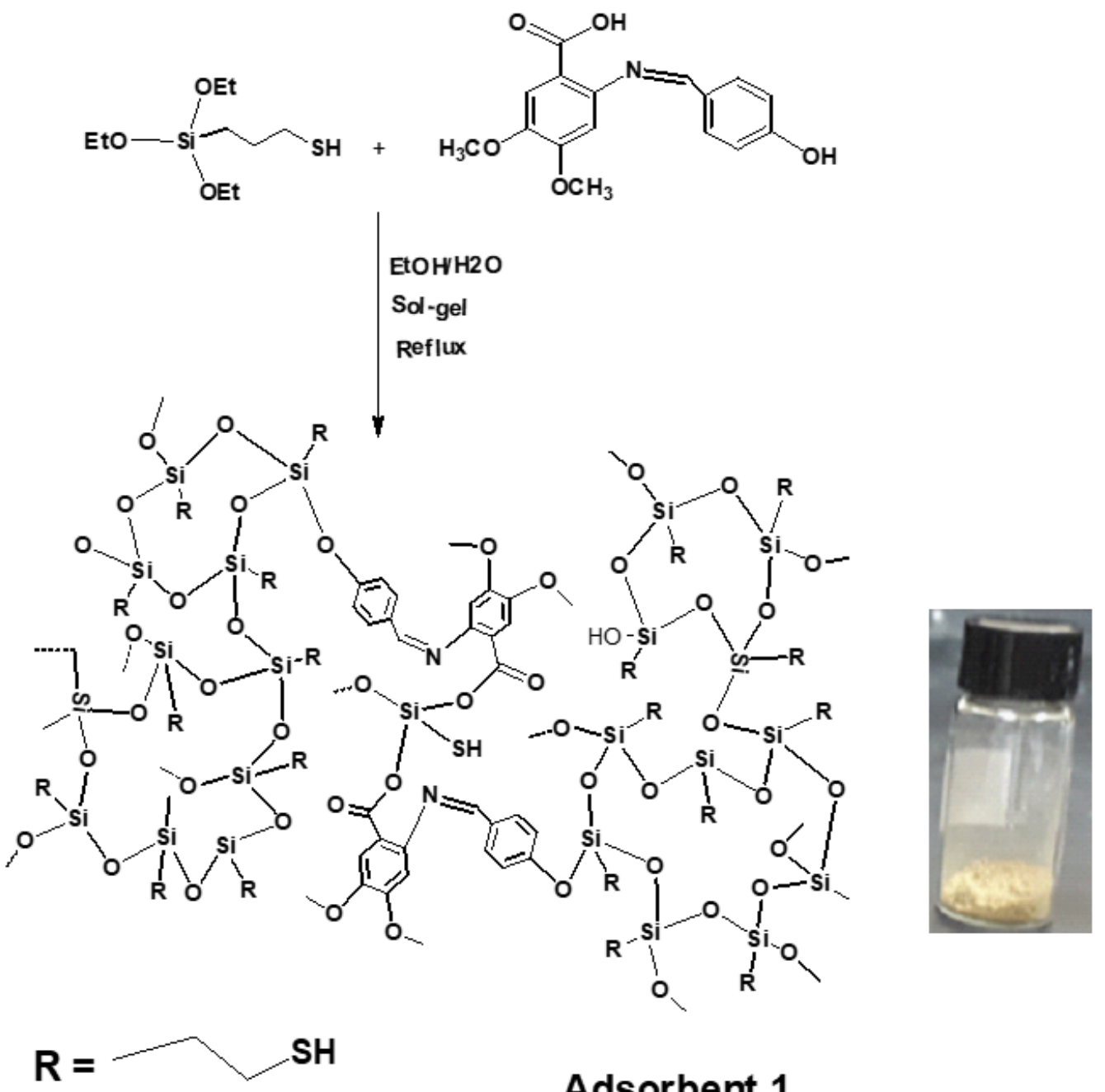

\section{Adsorbent 1}

Scheme 2. The synthesis of adsorbent 1 .

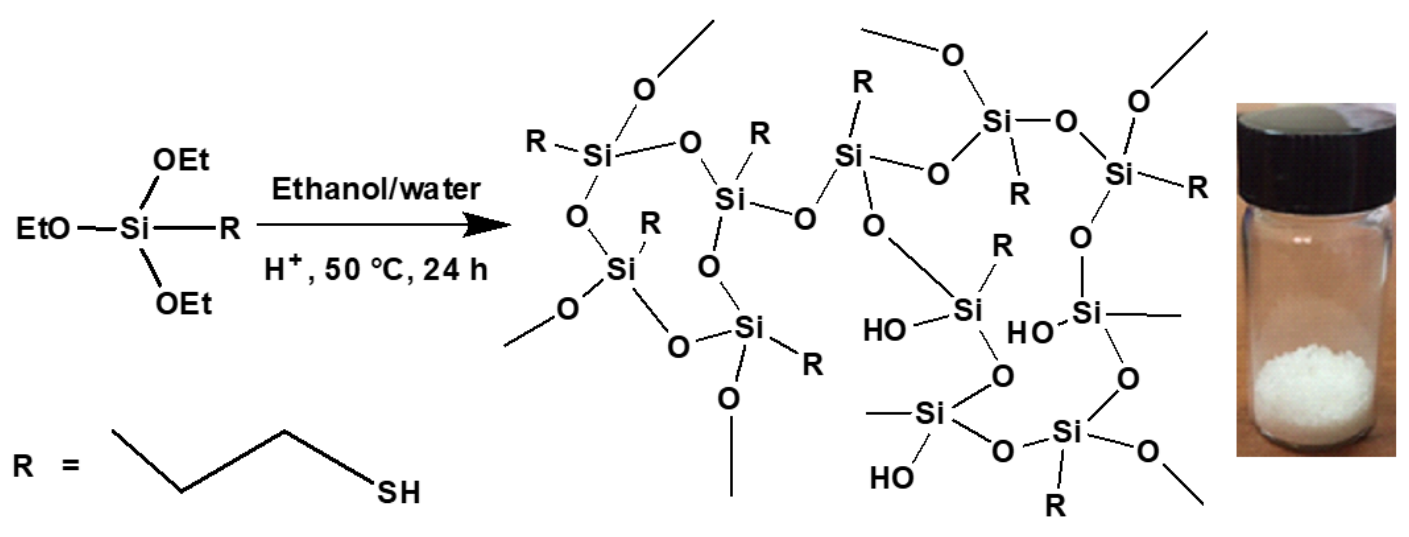

propyl-1-thiol

Adsorbent -2

Scheme 3. Preparation of adsorbent 2. 


\subsection{Sorption Experiment}

\subsection{1. $\mathrm{pH}$ Optimization}

The effects of $\mathrm{pH}$ on the adsorption of $\mathrm{Pb}(\mathrm{II})$ by adsorbents $\mathbf{1}$ and $\mathbf{2}$ was investigated at room temperature. Adsorption checks were carried out by adding $10 \mathrm{mg}$ of adsorbent $\mathbf{1}$ or $\mathbf{2}$ to each flask in a series of $100 \mathrm{~mL}$ Erlenmeyer flasks. To each flask, $50 \mathrm{~mL}$ of $\mathrm{Pb}$ (II) solution (25.52 mg/L) was added. Hydrochloride acid ( $\mathrm{HCl} ; 0.5 \mathrm{M})$ and sodium hydroxide $(\mathrm{NaOH} ; 0.5 \mathrm{M})$ were used to adjust the initial $\mathrm{pH}$ of the solutions between 2 and 7. A pH meter was used to measure the $\mathrm{pH}$ of the solutions. Each suspension was stirred at room temperature for $2 \mathrm{~h}$ at $25^{\circ} \mathrm{C}$ over various $\mathrm{pH}$ ranges $(2.0,4.0,6.0$, and 7.0). The solution was then filtered, and the amount of $\mathrm{Pb}$ (II) ions in the filtrate was analyzed for residual $\mathrm{Pb}(\mathrm{II})$ ions using inductively coupled plasma mass spectrometry (ICP-MS) in triplicate.

\subsubsection{Effect of Contact Time for $\mathrm{Pb}(\mathrm{II})$}

The $1000 \mathrm{mg} / \mathrm{L}$ standard solution of lead $\mathrm{Pb}(\mathrm{II})$ ions was diluted with deionized water to obtain $50 \mathrm{~mL}$ of $40 \mathrm{mg} / \mathrm{L}$. Adsorption checks were carried out by adding $20 \mathrm{mg}$ of each adsorbents 1 and 2 to three Erlenmeyer flasks (100 mL). To each flask, $50 \mathrm{~mL}$ of $\mathrm{Pb}$ (II) solution (of $40 \mathrm{mgL}^{-1}$ ) was added. The $\mathrm{pH}$ of solutions was adjusted to the optimum values $(6.5 \pm 0.2)$. The mixture was stirred constantly at $300 \mathrm{rpm}$ in order to allow contact at different contact times. Five milliliter portions from each solution were filtered at measured time intervals ( 0 to $340 \mathrm{~min}$ ), and the residual $\mathrm{Pb}$ (II) ion concentrations were measured using ICP-MS in triplicate. Results expressed as ppm for adsorbents $\mathbf{1}$ and 2, respectively. The sorption capacities at equilibrium $\left(\mathrm{mg} \mathrm{g}^{-1}\right)$ and the percentage adsorption (\% ads) of adsorbents 1 and 2 were calculated using the following Equations (1) or (2) [4]:

$$
\begin{gathered}
q e=\left[C_{0}-C_{e}\right] / m \times V \\
\% \text { ads }=\left[C_{0}-C_{e}\right] / C_{0} \times 100
\end{gathered}
$$

where $q_{e}$ is the equilibrium uptake capacity $\left(\mathrm{mg} \mathrm{g}^{-1}\right), C_{0}$ is the initial concentration of $\mathrm{Pb}(\mathrm{II})\left(\mathrm{mg} \mathrm{L}^{-1}\right)$, $C_{e}$ is the equilibrium concentration of $\mathrm{Pb}$ (II) expressed in $\mathrm{mg} \mathrm{L}^{-1}, \mathrm{~V}$ is the volume of aqueous solutions (L), and $\mathrm{m}$ is the weight of the adsorbent 1 or $2(\mathrm{~g})$.

\section{Results and Discussion}

\subsection{Synthesis of Adsorbents 1 and $\mathbf{2}$}

The aim of this work was to improve the sorption efficiency of silica for removal of toxic heavy metals from polluted water. For this purpose, two mesoporous silica materials (adsorbents) were prepared. Adsorbent 1 was silica functionalized with Schiff base-propyl-thiol and adsorbent 2 was silica functionalized with propyl-thiol. The Schiff base was synthesized from 2-amino-4,5-dimethoxybenzoic acid and 4-hydroxybenzaldehyde via a condensation reaction in ethanol using acetic acid as a catalyst (Scheme 1). The Schiff base purity was confirmed by FTIR (Figure 1), ${ }^{1} \mathrm{H}$ and ${ }^{13} \mathrm{C}$ NMR spectroscopy (See Supporting Information; Supplementary Materials, Figures S1 and S2). The synthetic route of adsorbent $\mathbf{1}$ is shown in Scheme 2, the organic precursor 3-(triethoxysilyl) propane-1-thiol was added to a suspension containing Schiff base 2-(4-hydroxybenzylideneamino)-4,5-dimethoxybenzoic acid), ethanol, water and ammonia as a catalyst to obtain Schiff base-thiol silica gel (adsorbent 1) through the sol-gel reaction. The silica functionalized with propyl-thiol (adsorbent 2) was prepared by co-condensation (direct synthesis) of the organic precursor 3-(triethoxysilyl) propane-1-thiol in the presence of ammonia as a catalyst (Scheme 3). 


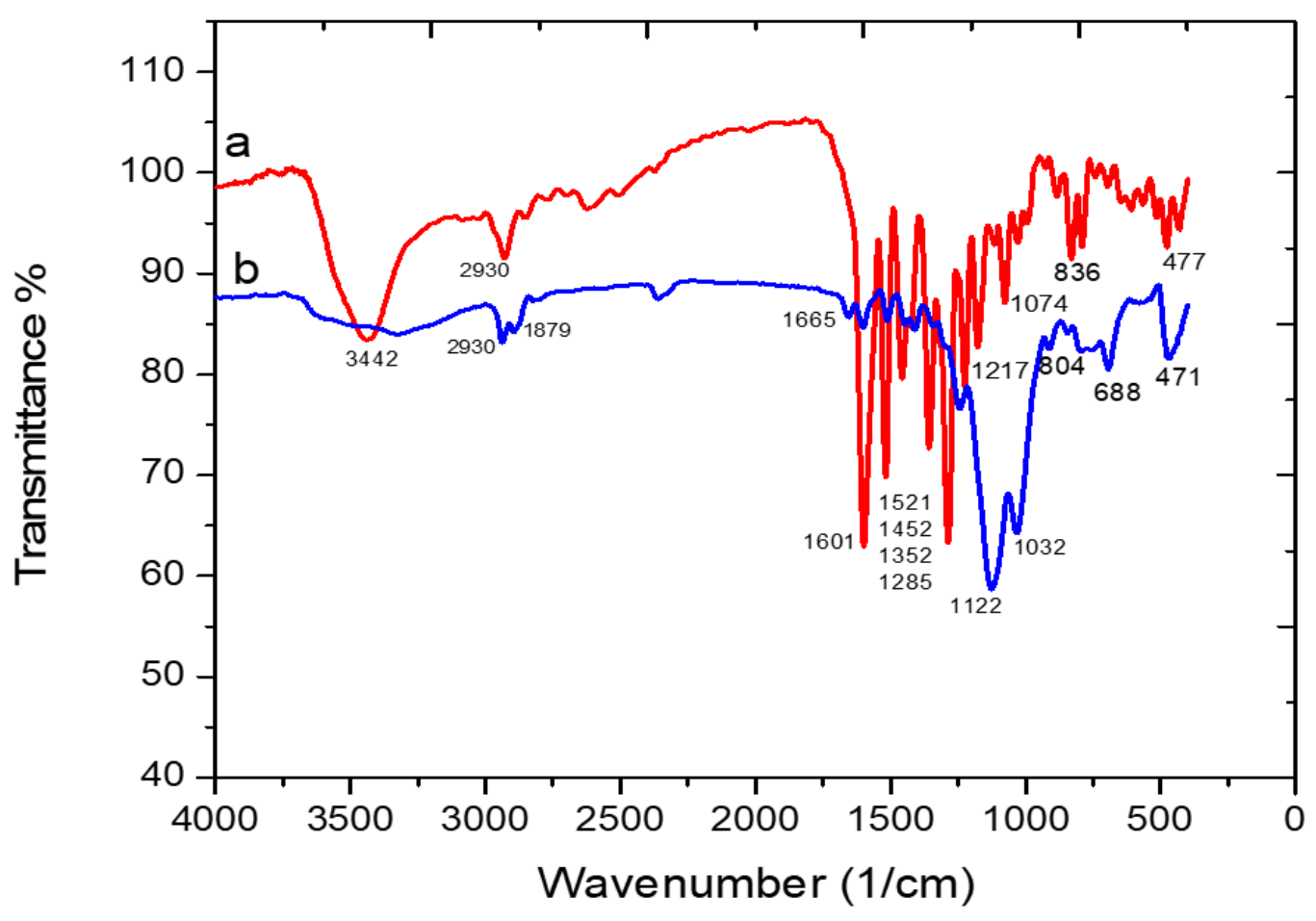

Figure 1. FTIR spectra of (a) free Schiff base and (b) adsorbent 1.

The two adsorbents (1 and 2 ) were isolated as yellowish and white powders, respectively. The hybrid materials were washed several times with water, ethanol, and dried under vacuum before characterization. The synthesized adsorbents were completely characterized by FTIR, XRD, SEM, energy-dispersive X-ray spectroscopy (EDX), TGA, and BET analyses.

\subsection{Characterization}

\subsubsection{The FT-IR Spectra of Free Schiff Base and the Schiff Base Functionalized Silica (Adsorbent 1)}

The FT-IR spectra of free Schiff base and the Schiff base functionalized silica (adsorbent 1) are shown in Figure 1. Figure 1a displays the characteristic peaks of free Schiff base. The broad band at $3442 \mathrm{~cm}^{-1}$ was assigned to the vibration of the phenolic group $v(\mathrm{OH})$. In addition, the absorptions at 1601 and $1521 \mathrm{~cm}^{-1}$ in the free Schiff base were due to carbonyl $v(C=O)$ and azomethine $v(C=N)$, respectively. These vibrations appeared at lower frequencies due to strong intramolecular hydrogen bonds in the solid state of the free Schiff base. The weak peaks observed at $2921 \mathrm{~cm}^{-1}$ belonged to the stretching modes of the aliphatic -C-H bond. Figure 1b, shows the FT-IR spectrum of adsorbent 1 . The characteristic vibration of the phenolic group $v(\mathrm{OH})$ at $3442 \mathrm{~cm}^{-1}$ in free Schiff base (Figure 1a) was decreased indicating successful functionalization of Schiff base on the silica surface. However, adsorbent 1 displayed broad bands in the region of 3250 to $3600 \mathrm{~cm}^{-1}$, which were assigned to the silanol stretching modes $v(\mathrm{Si}-\mathrm{OH})$. The intensive absorption peaks observed at $1122-1032 \mathrm{~cm}^{-1}$ are due to asymmetric $v(\mathrm{Si}-\mathrm{O}-\mathrm{Si})$ and the band at $804 \mathrm{~cm}^{-1}$ is due to symmetric stretching vibrations of $\mathrm{Si}-\mathrm{O}-\mathrm{Si}$ [33]. The weak peaks observed at $2930 \mathrm{~cm}^{-1}$ belong to the stretching modes of the aliphatic $-\mathrm{C}-\mathrm{H}$ bond. The appearance of bands around $1665-1402 \mathrm{~cm}^{-1}$ were caused by $\mathrm{C}=\mathrm{O}, \mathrm{C}=\mathrm{N}$, and $\mathrm{C}=\mathrm{C}$ vibrations, confirming the anchoring of the organic molecule (Schiff base) onto the silica surface [34]. Moreover, the characterization features of adsorbent 1 compared with the free Schiff base were the shift of the carbonyl group from $1601 \mathrm{~cm}^{-1}$ (in free Schiff base) to $1665 \mathrm{~cm}^{-1}$ (in adsorbent 1) and the disappearance of the thiol S-H peak at $2556 \mathrm{~cm}^{-1}$ compared to adsorbent 2. 


\subsubsection{The FT-IR Spectra of Adsorbent 1 before and after Loading $\mathrm{Pb}$ (II) Ions}

The FT-IR spectra of adsorbent $\mathbf{1}$ before and after loading $\mathrm{Pb}(\mathrm{II})$ ions are shown in Figure 2. It can be seen that the results for the $\mathrm{Pb}(\mathrm{II})$ ions loaded sample were almost same as the pre-adsorption sample, However, some of the bands after lead ions were loaded shifted to a lower value than that of the pre-adsorption sample, confirming the adsorption of the $\mathrm{Pb}(\mathrm{II})$ ions on the silica surface. This suggests the involvement of the oxygen atom of the carboxylate anion with the azomethine nitrogen and the $\mathrm{Pb}(\mathrm{II})$ ion [35]. The infrared spectrum in Figure $2 \mathrm{~b}$ revealed the asymmetric stretching vibration of $v_{\mathrm{as}}\left(\mathrm{COO}^{-}\right)$of adsorbent 1 at $1665 \mathrm{~cm}^{-1}$ was shifted to a lower wave number $\left(1642 \mathrm{~cm}^{-1}\right)$ after the $\mathrm{Pb}$ (II) ion was loaded, indicating that the lead ion coordination took place via the oxygen atom of the carboxylate anion [36].

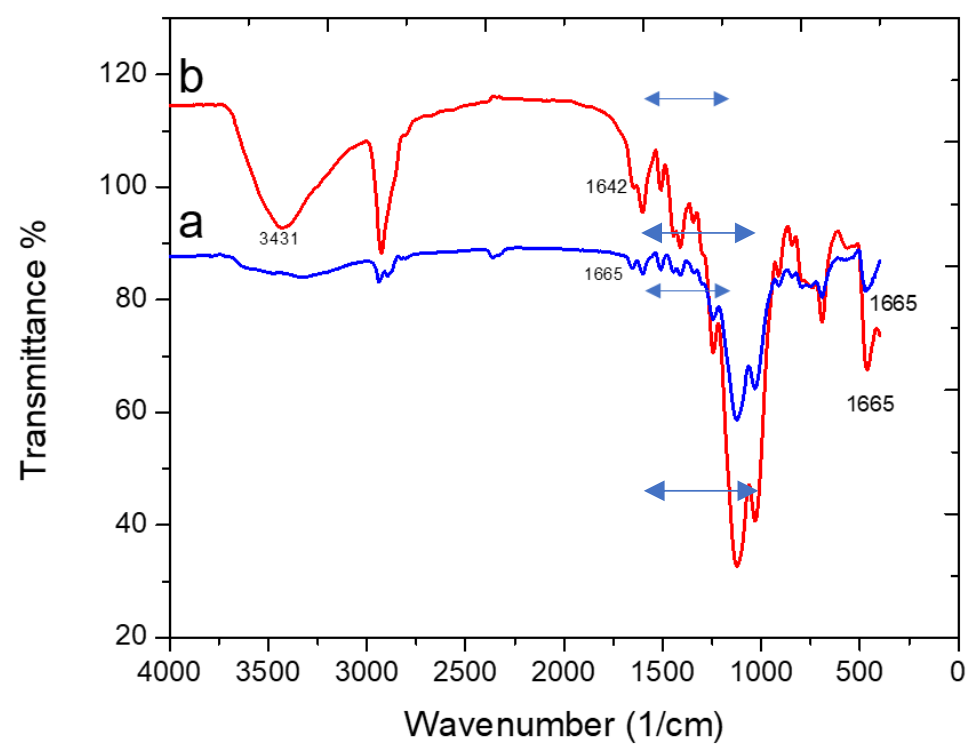

Figure 2. FTIR absorption spectrum of adsorbent 1, (a) before absorption and (b) after adsorption.

\subsubsection{The FT-IR Spectra of Adsorbent 2 before and after Loading $\mathrm{Pb}(\mathrm{II})$ Ions}

Figure 3 shows the FT-IR spectroscopy results of adsorbent 2 samples taken before and after $\mathrm{Pb}(\mathrm{II})$ ion adsorption studies. The spectrum of synthesized adsorbent 2 before adsorption studies (Figure 3a) presents a broad band centered at $3495 \mathrm{~cm}^{-1}$, which was assigned to the $\mathrm{OH}$ vibrations in the silica framework, while the strong absorption peak located at $1128 \mathrm{~cm}^{-1}$ was due to asymmetric $v(\mathrm{Si}-\mathrm{O}-\mathrm{Si})$, and the band at $804 \mathrm{~cm}^{-1}$ was due to symmetric $v(\mathrm{Si}-\mathrm{O})$ stretching vibrations [33]. The weak peaks observed at $2921 \mathrm{~cm}^{-1}$ belong to the stretching modes of the aliphatic $-\mathrm{C}-\mathrm{H}$ bond. The characteristic thiol S-H functional group peak was detected at $2556 \mathrm{~cm}^{-1}$ confirming the anchoring of the organic molecule (propyl-thiol) onto the silica surface. Compared with the spectrum of adsorbent 2 after $\mathrm{Pb}$ (II) ion loading (Figure 3b), it can be seen that the results for the lead ion loaded sample were similar to that before adsorption, except the intense broad peak centered at $3431 \mathrm{~cm}^{-1}$ was attributed to coordinative water in the coordination sphere of $\mathrm{Pb}$ (II) Schiff base complex. The characteristic peaks at $2556 \mathrm{~cm}^{-1}$ has diminished, suggesting that adsorbent 2 interacted with soft Lewis acid $\mathrm{Pb}$ (II) ions through the thiol groups.

\subsubsection{XRD of Adsorbents 1 and 2}

The XRD patterns of Schiff base-functionalized silica (adsorbent 1) and propyl-1-thiol functionalized silica (adsorbent 2) are illustrated in Figure 4. The XRD patterns of both adsorbents 1 and 2 showed weak broad peaks at a low $2 \theta$ angle $\left(7.47^{\circ}\right)$ and broad peaks at a high $2 \theta$ angle $\left(20.21^{\circ}\right)$ for adsorbent 1 and at $23.57^{\circ}$ for adsorbent 2, indicating the amorphous nature of the silica in both adsorbents [37]. Furthermore, the shift of the broad peak at a high $2 \theta$ angle $\left(23.57^{\circ}\right)$ for adsorbent 
2 to $20.21^{\circ}$ for adsorbent 1 suggests structural perturbations resulting from the incorporation of the Schiff base within the silica framework [34]. The XRD patterns of adsorbent $\mathbf{1}$ show sharp peaks at $37.73,43.79,64.29,77.47,81.81$, and 98.37 of 20 . These sharp peaks were due to the ligand (Schiff base) immobilized on the surface of silica [38].

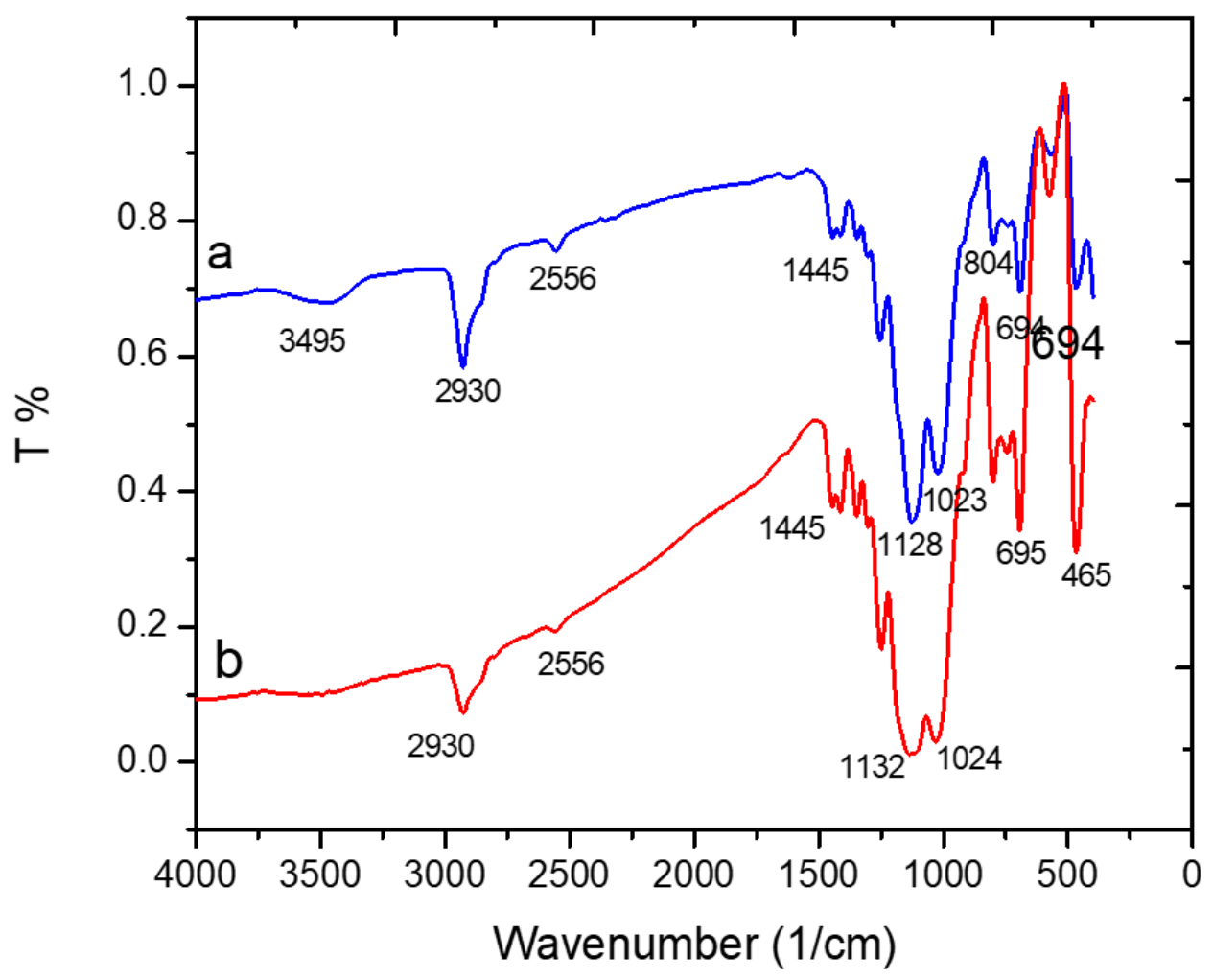

Figure 3. FTIR absorption spectrum of adsorbent (2), (a) before absorption and (b) after adsorption.

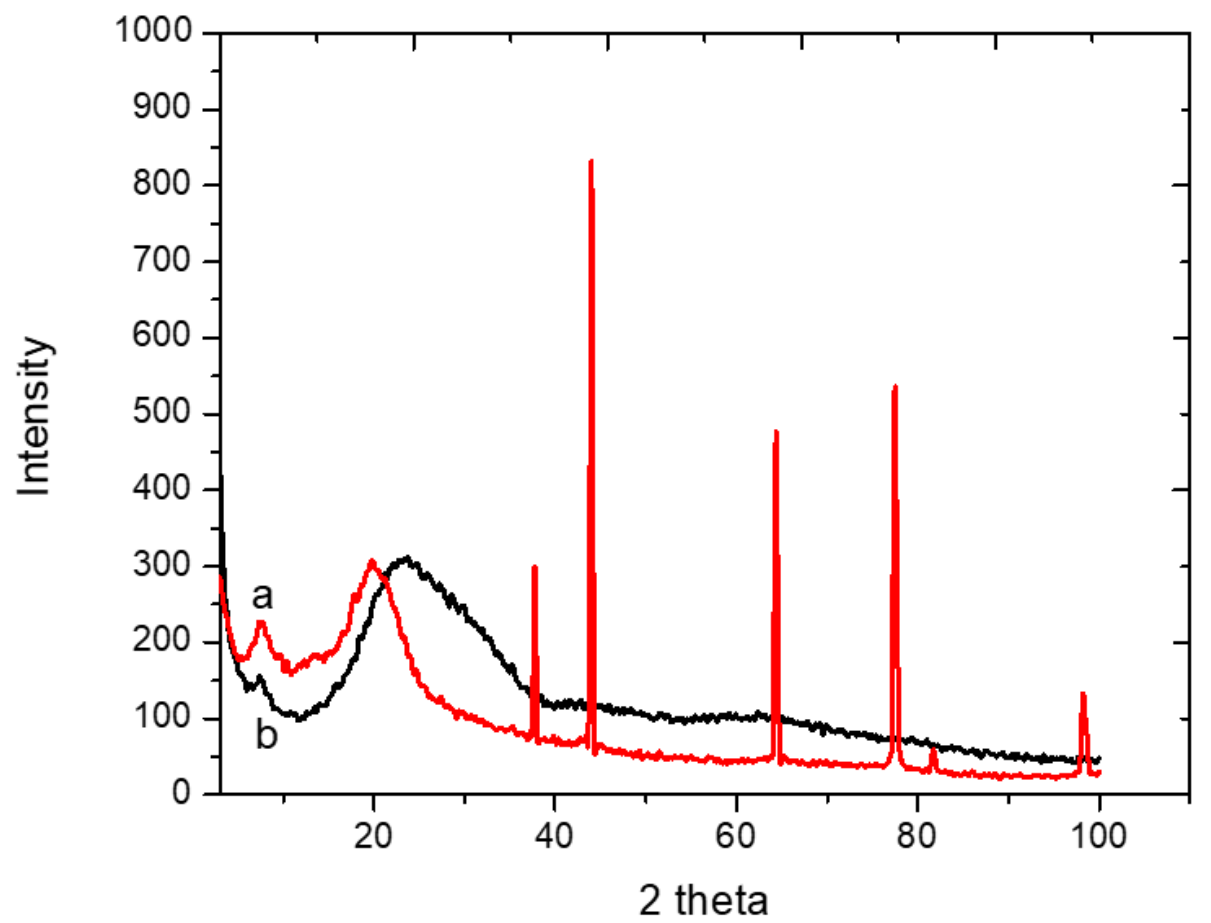

Figure 4. The X-ray diffraction (XRD) patterns of (a) adsorbent $\mathbf{1}$ and (b) adsorbent 2. 


\subsubsection{SEM of Adsorbents 1}

The SEM images of adsorbent $\mathbf{1}$ are shown in Figure 5. As revealed in Figure 6, adsorbent $\mathbf{1}$ showed uniform distribution of spherical particles with different sizes. The presence of the organic components (Schiff base and propyl thiol groups) on the overall surface caused the surface of adsorbent $\mathbf{1}$ to be rough as a result of the microporous structure. Furthermore, the EDX pattern of adsorbent $\mathbf{1}$ is shown in Figure 6. EDX data in Table 1 confirm the formation of adsorbent 1, as shown by the Si, S, N, $\mathrm{C}$, and $\mathrm{O}$ peaks, thus confirming the presence of organic components (Schiff base and propyl thiol groups) on the silica surface.

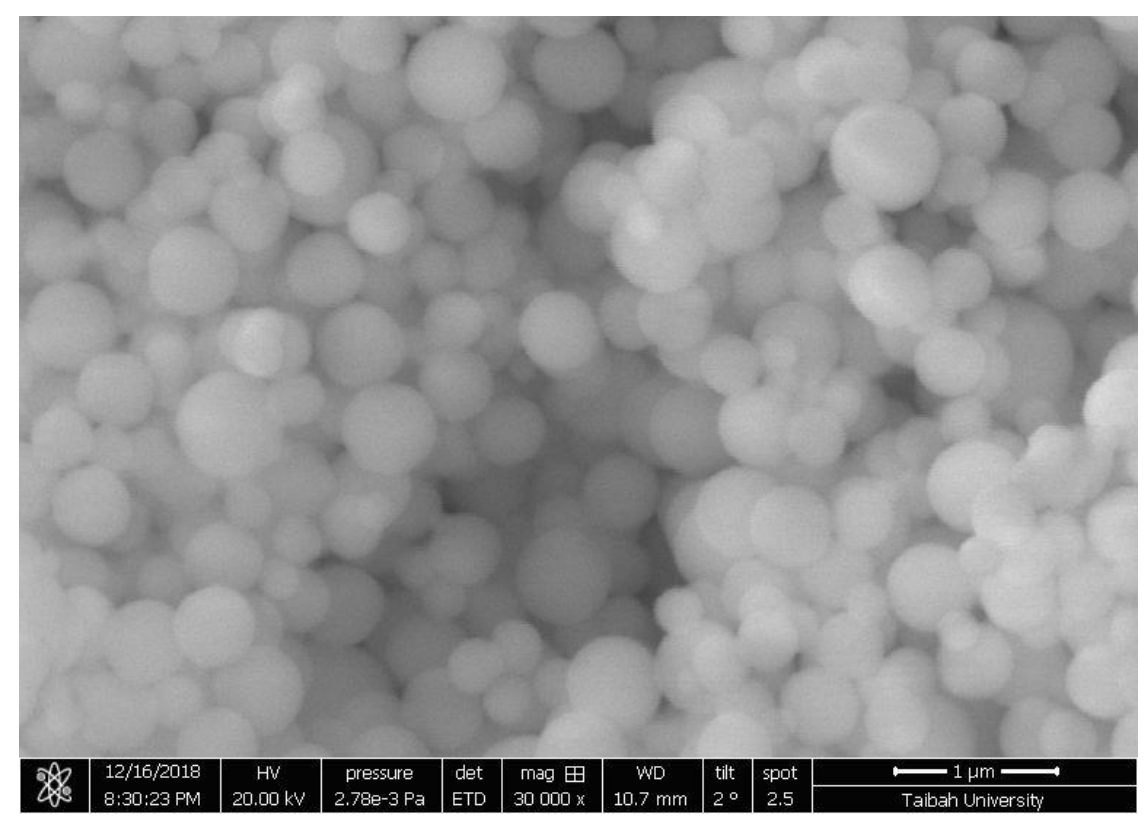

Figure 5. Scanning electron microscopy (SEM) images of pure adsorbent $\mathbf{1}$ before adsorption.

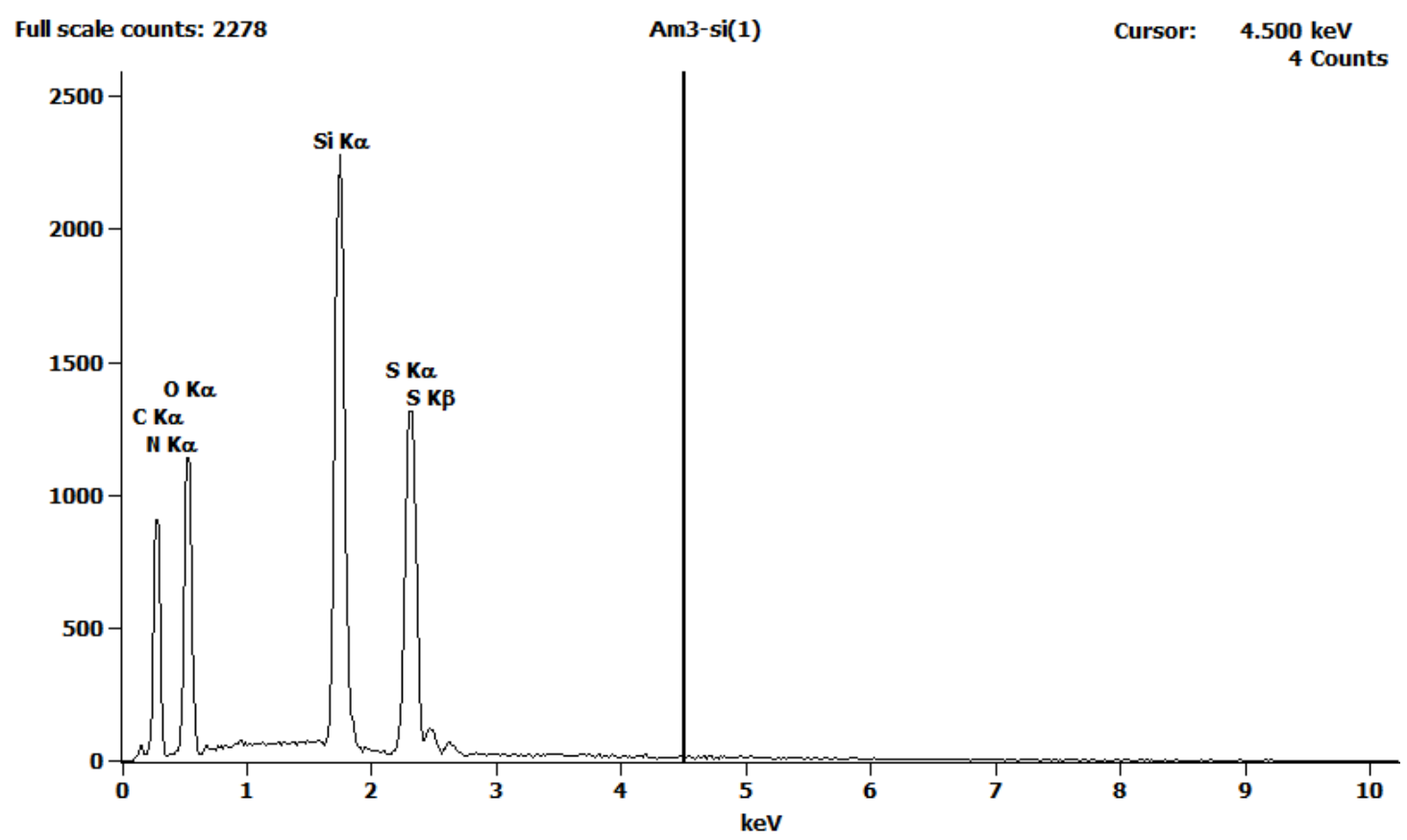

Figure 6. Energy-dispersive X-ray spectroscopy (EDX) spectrum of adsorbent $\mathbf{1}$ before adsorption. 
Table 1. (EDX) data of adsorbent $\mathbf{1}$ before adsorption.

\begin{tabular}{ccc}
\hline Element & Weight $\%$ & Atom $\%$ \\
\hline $\mathrm{C}$ & 20.99 & 34.36 \\
$\mathrm{~N}$ & 1.19 & 1.66 \\
$\mathrm{O}$ & 22.46 & 27.59 \\
$\mathrm{Si}$ & 28.09 & 19.66 \\
$\mathrm{~S}$ & 27.28 & 16.73 \\
Total & 100.00 & 100.00 \\
\hline
\end{tabular}

Figure 7 presents an SEM micrograph of $\mathrm{Pb}$ (II) ions loaded onto adsorbent 1. SEM analysis revealed that adsorbent $\mathbf{1}$ displayed agglomerated spherical particles with different sizes and granular morphologies. The accompanying EDX spectrum of the silica-functionalized Schiff base shown in Figure 8 confirms the presence of $\mathrm{Pb}$ (II) ions on the surface of adsorbent 1 . The EDX data in Table 2 confirmed that adsorbent 1 was very effective in removing $\mathrm{Pb}$ (II) ions from aqueous solutions. The EDX results were in good agreement with the results obtained by inductively coupled plasma mass spectrometry (ICP-MS).

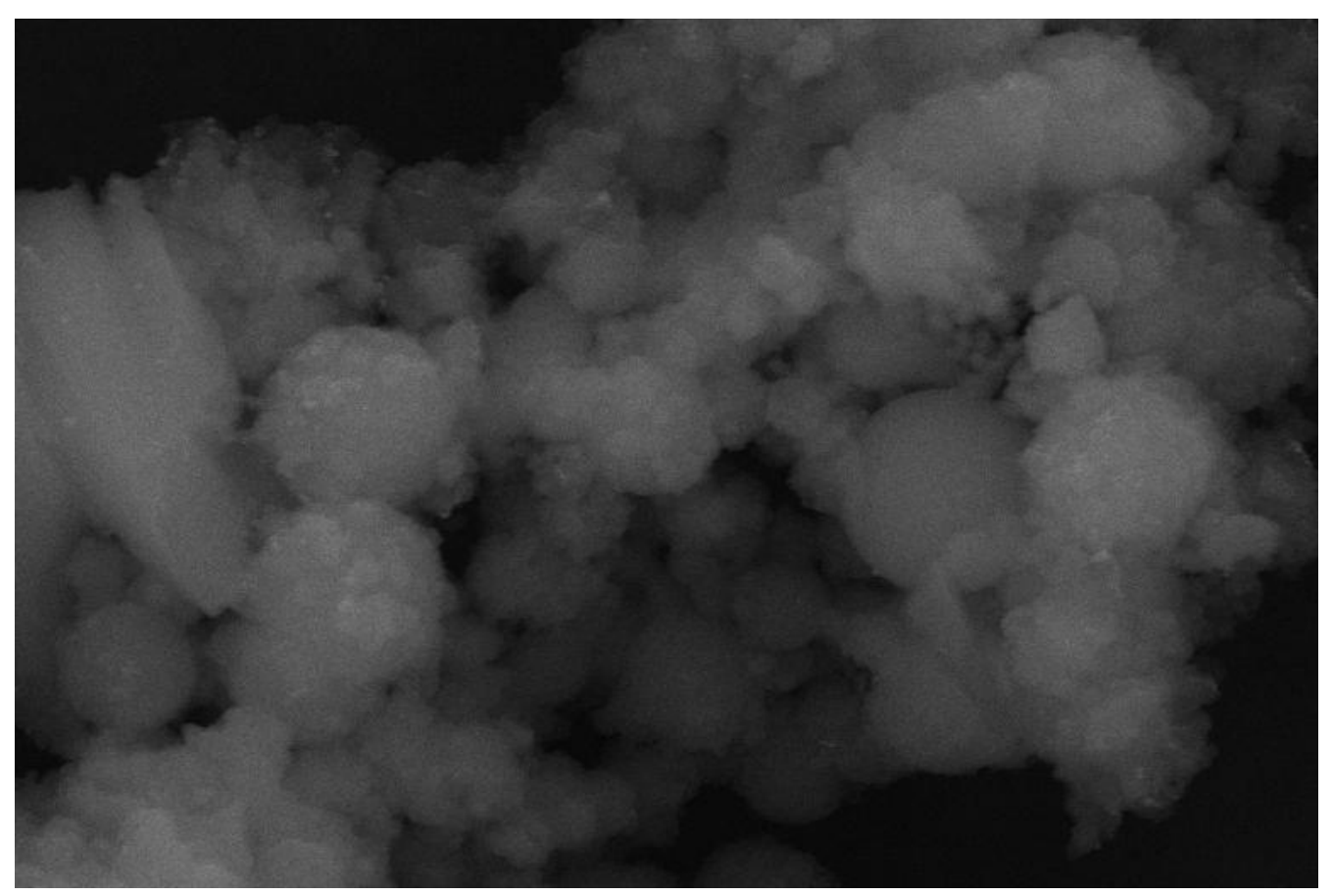

Figure 7. SEM images of adsorbent $\mathbf{1}$ after adsorption.

Table 2. (EDX) data of adsorbent 1 after adsorption.

\begin{tabular}{ccc}
\hline Element & Weight $\%$ & Atom $\%$ \\
\hline $\mathrm{C}$ & 24.07 & 36.73 \\
$\mathrm{~N}$ & 1.78 & 2.33 \\
$\mathrm{O}$ & 29.81 & 34.16 \\
$\mathrm{Si}$ & 21.60 & 14.10 \\
$\mathrm{~S}$ & 22.08 & 12.63 \\
$\mathrm{As}$ & 0.00 & 0.00 \\
$\mathrm{~Pb}$ & 0.66 & 0.06 \\
Total & 100.00 & 100.00 \\
\hline
\end{tabular}






Figure 8. (EDX) spectrum of adsorbent 1 after adsorption.

\subsubsection{Field Emission Scanning Microscope (FESEM) of Adsorbent 2}

Figure 9 shows the field emission scanning microscope (FESEM) image of adsorbent 2. As shown in Figure 10, the hybrid is spherical with a rough surface. The SEM image showed a homogeneous material with pores covering the entire structure. The pore size varied between 2 and $8 \mu \mathrm{m}$. The presence of the overall surface of the propyl thiol groups caused the surface of adsorbent 2 to be rough with a microporous structure. Moreover, the EDX pattern of adsorbent 2 (Figure 10) confirms the purity of adsorbent 2 and also confirms the presence of propyl thiol groups on the silica surface. The EDX spectrum also presents a minor peak of $\mathrm{Au}$ and $\mathrm{Cl}$ that resulted from the thin film of gold deposited on the insulating sample in order to make it conductive and, hence, easy to visualize using SEM.

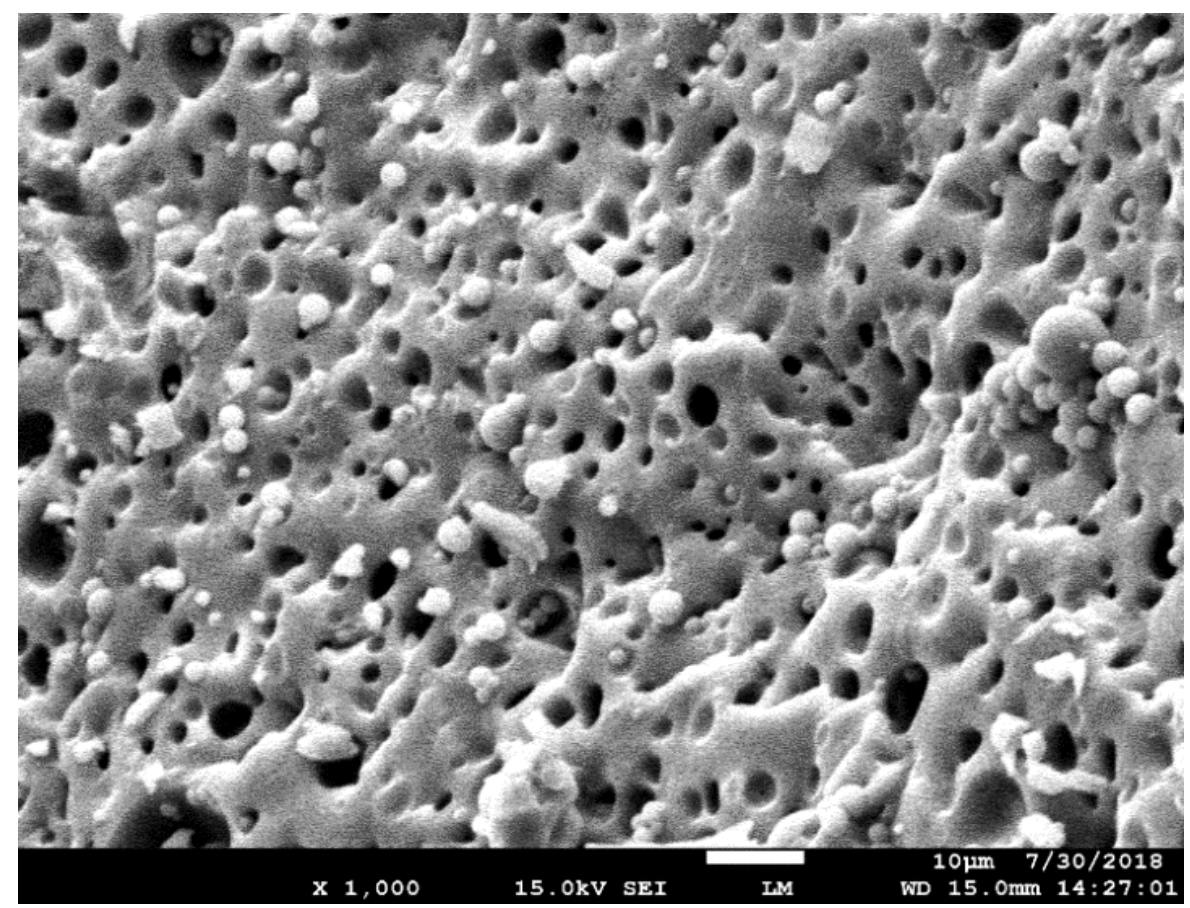

Figure 9. Field emission scanning electron microscopy (FESEM) images of adsorbent 2 before adsorption. 


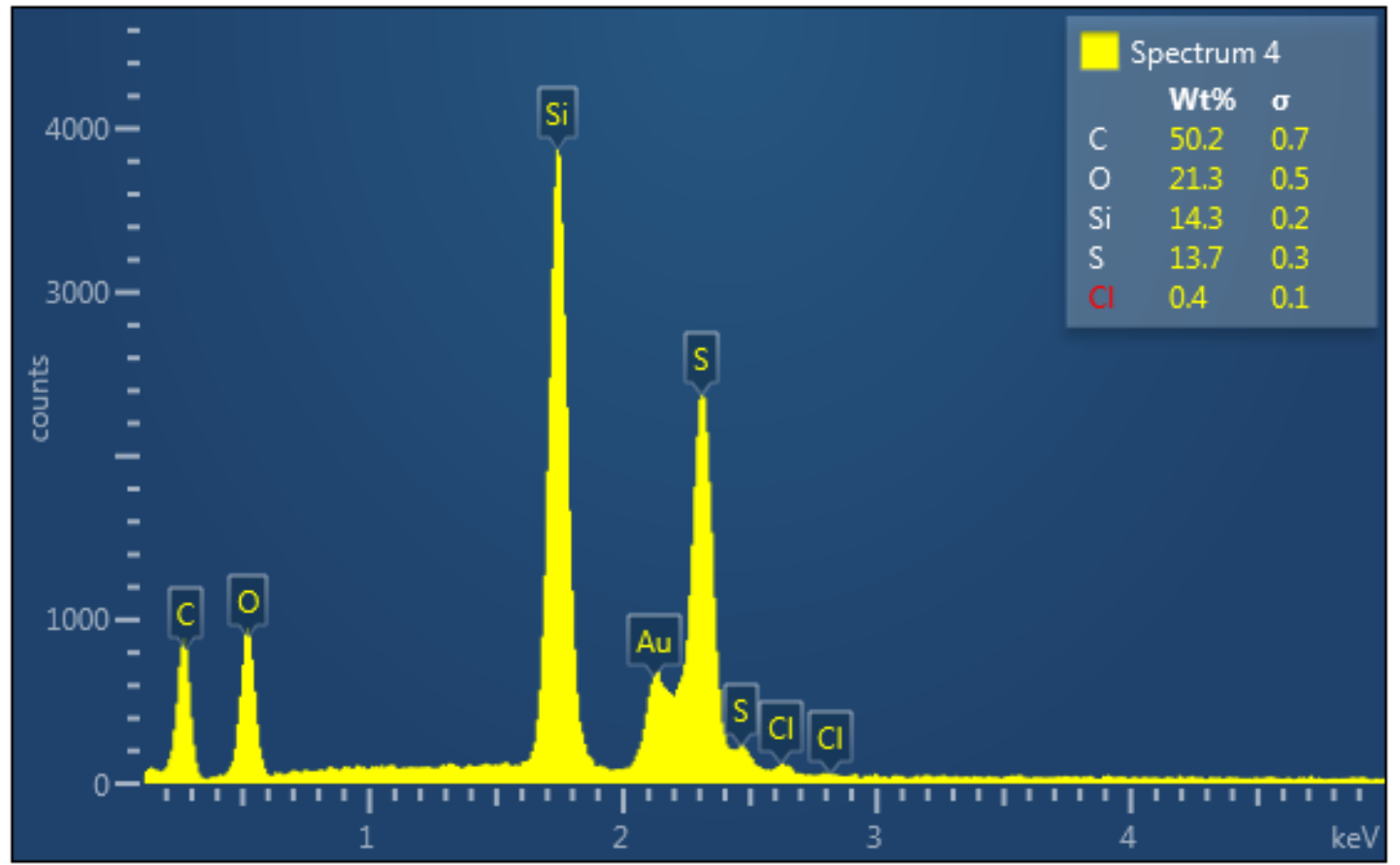

Figure 10. EDX images of adsorbent 2 (inset is the EDX data of adsorbent 1 before adsorption).

Figure 11 presents an $\mathrm{SEM}$ micrograph of $\mathrm{Pb}$ (II) ions loaded onto adsorbent 2. SEM analysis revealed that adsorbent 2 displayed spherical particles with different sizes and rough morphology. The accompanying EDX spectrum of the silica-functionalized Schiff base, shown in Figure 12, confirms the presence of $\mathrm{Pb}$ (II) ions on the surface of adsorbent 2 (see Table 3). However, the EDX spectrum confirmed that adsorbent 2 was also effective in removing $\mathrm{Pb}$ (II) ions from aqueous solutions. EDX studies have shown that both adsorbents (1 and $\mathbf{2})$ have strong affinities to divalent metal cations $(\mathrm{Pb}(\mathrm{II}))$.

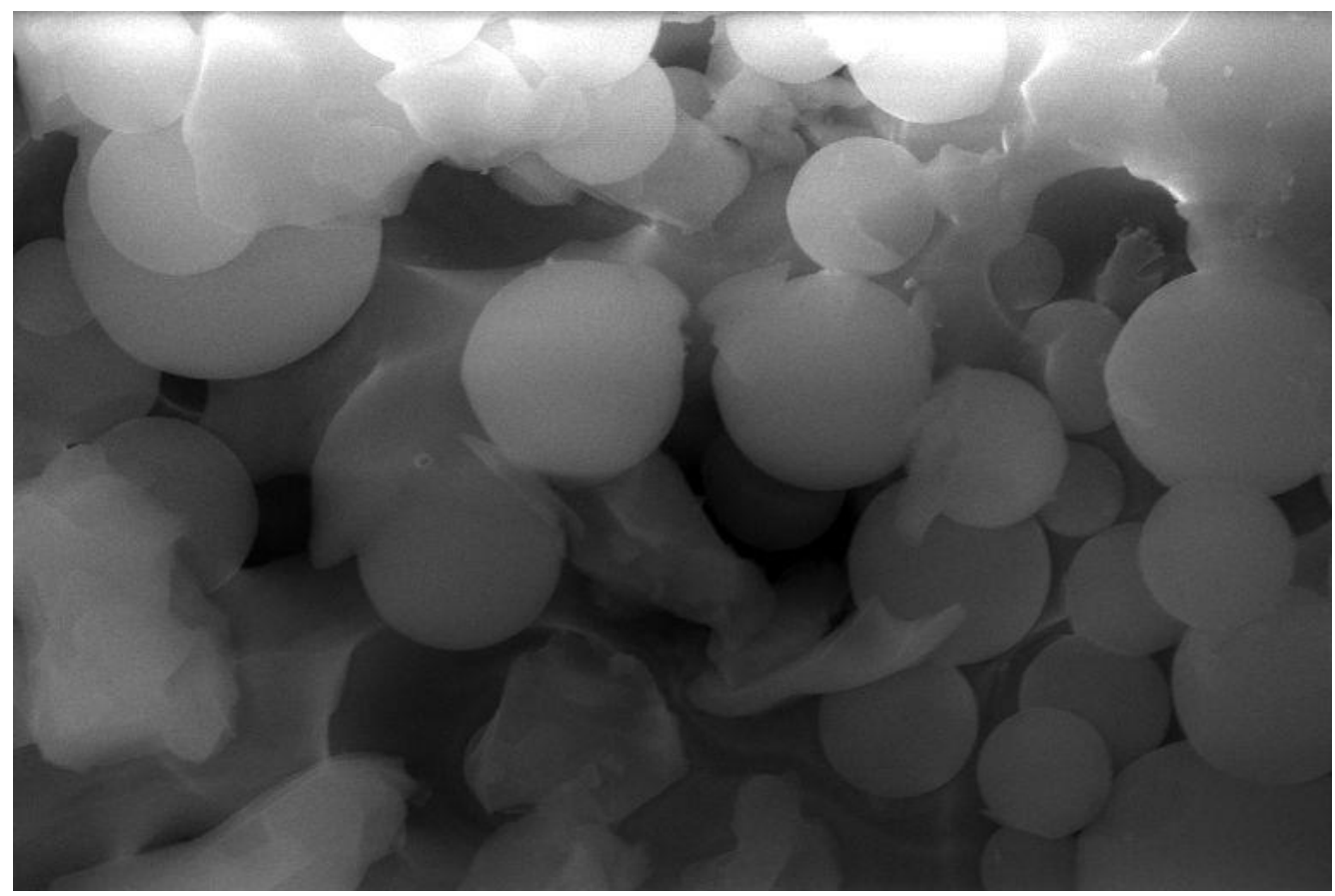

Figure 11. SEM images of adsorbent 2 after adsorption. 


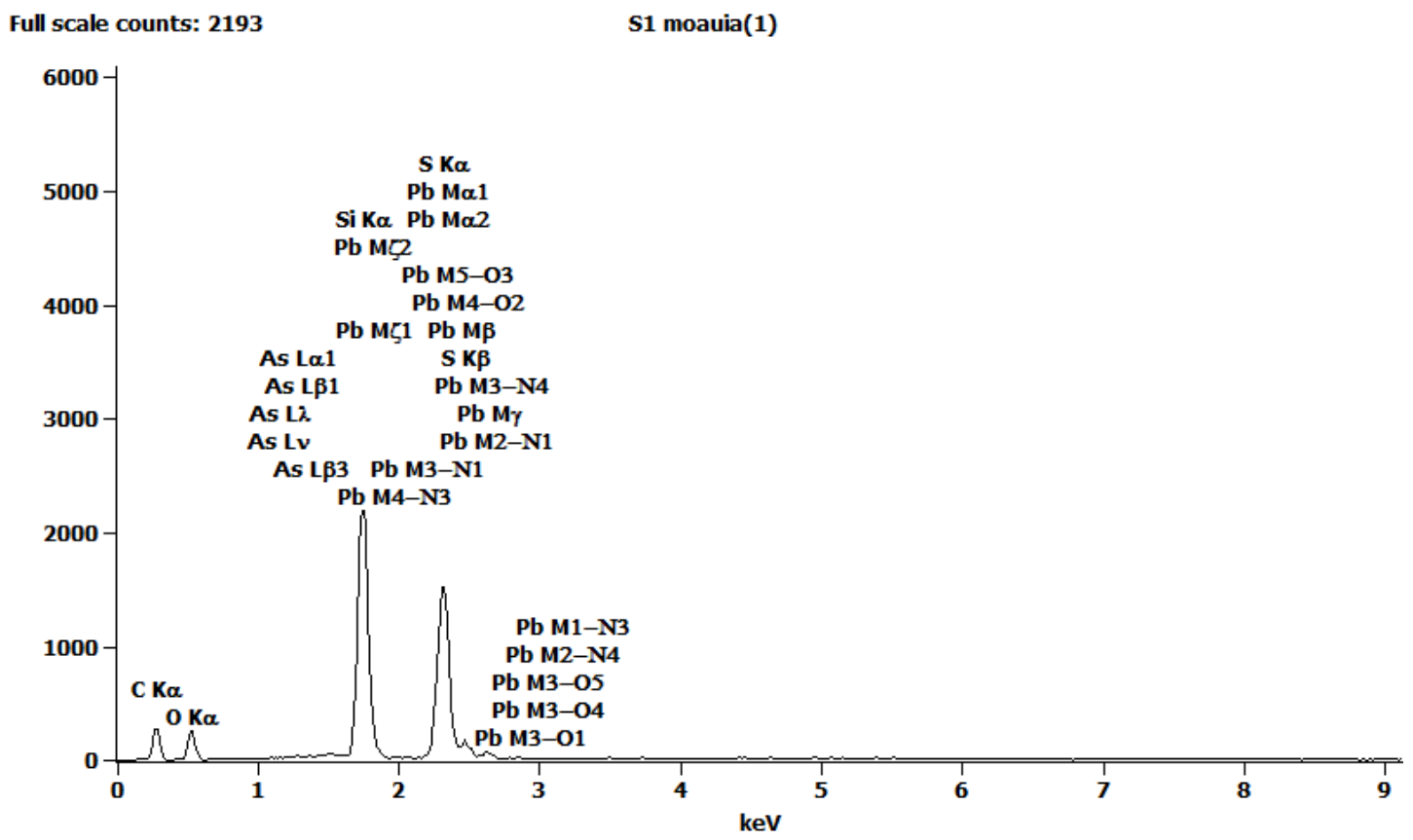

Figure 12. EDX spectrum of adsorbent 2 after adsorption.

Table 3. EDX data of adsorbent 2 after adsorption.

\begin{tabular}{ccc}
\hline Element & Weight \% & Atom \% \\
\hline $\mathrm{C}$ & 30.19 & 46.20 \\
$\mathrm{O}$ & 24.74 & 28.42 \\
$\mathrm{Si}$ & 21.87 & 14.32 \\
$\mathrm{~S}$ & 18.54 & 10.63 \\
$\mathrm{As}$ & 0.10 & 0.02 \\
$\mathrm{~Pb}$ & 4.55 & 0.40 \\
Total & 100.00 & 100.00 \\
\hline
\end{tabular}

\subsubsection{TGA of Adsorbent 1 and 2}

The TGA thermal details of adsorbents 1 and $\mathbf{2}$ are presented in Figure 13. The thermogram of adsorbent 1 (Figure 13a) shows that there are essentially two regions of weight loss; in the first region, a slight weight lost in the range of 45 to $285^{\circ} \mathrm{C}$ due to the loss of physiosorbed solvents used in the preparation $\left(2.85 \%\right.$ ) can be seen. The second region appears in the range of 285 to $475{ }^{\circ} \mathrm{C}$ (with lost weight equal to $28.1 \%$ and with DTG $\max$ at $346^{\circ} \mathrm{C}$ ) due to decomposition of the Schiff base and propyl-thiol groups immobilized on the silica surface [39]. The remaining weight loss in the range of 475 to $885^{\circ} \mathrm{C}$ (with total weight loss equal to $26.23 \%$ ) was due to the condensation of the hydroxyl group silanol (Si-O-OH) to yield siloxane bonds (Si-O-Si) [38]. At $885^{\circ} \mathrm{C}$, adsorbent 1 around $57.18 \%$ was degraded, leaving $42.82 \%$ behind as residue.

\subsubsection{Surface Properties of Adsorbents 1 and 2}

Using nitrogen adsorption isotherms, the surface area, pore volume, and pore size of adsorbents 1 and 2 were measured. It is noted that adsorbent 1 exhibited a BET surface area of $22.0452 \mathrm{~m}^{2} / \mathrm{g}$, the pore volume (BJH) of adsorbent 1 was $0.120986 \mathrm{~cm}^{3} \mathrm{~g}^{-1}$ with pore sizes of $15.7644 \mathrm{~nm}$ (BET) and $22.7447 \mathrm{~nm}(\mathrm{BJH})$. On the other hand, adsorbent 2, which was prepared by direct hydrolysis and condensation of 3-(triethoxysilyl) propane-1-thiol, exhibited a BET surface area of $9.3475 \mathrm{~m}^{2} \mathrm{~g}^{-1}$. The pore volume (BJH) of adsorbent 2 was $0.049107 \mathrm{~cm}^{3} \mathrm{~g}^{-1}$ with pore sizes of $9.68719 \mathrm{~nm}$ (BET) and $25.0027 \mathrm{~nm}(\mathrm{BJH})$. The reduced surface area and pore volume of adsorbent 2 were due to the smaller 
size of the propyl-thiol group. The noticeable increase in the BET surface area of adsorbent $\mathbf{1}$ was attributed to the Schiff base and propyl-thiol groups anchored on the silica framework. This indicates that adding more organic moieties to silica framework results in a large surface area, which increases the possibility of extracting metal ions [40].

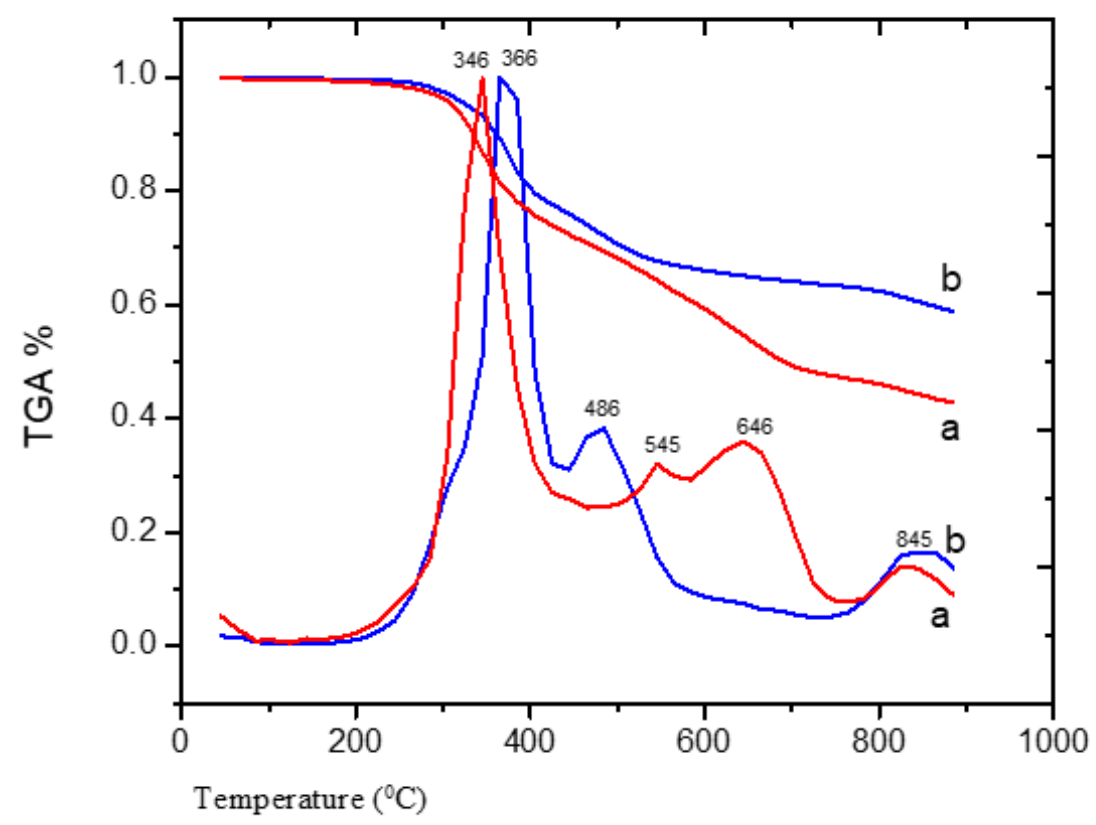

Figure 13. Thermogravimetric (TGA) curve of (a) adsorbent $\mathbf{1}$ and (b) adsorbent 2.

\subsection{Adsorption Study}

\subsubsection{Effects of $\mathrm{pH}$ on the Adsorption of $\mathrm{Pb}$ (II) by Adsorbent 1}

The effects of the $\mathrm{pH}$ value on the adsorption of $\mathrm{Pb}(\mathrm{II})$ ions by adsorbents $\mathbf{1}$ and $\mathbf{2}$ are shown in Figure 14. The results show an increase in percent adsorption (\% ads) for sorption of $\mathrm{Pb}$ (II) ions by both adsorbents with increasing $\mathrm{pH}$ reaching a maximum of $91.30 \%$ and $73.54 \%$ at $\mathrm{pH} 7.0$ for adsorbents 1 and 2 respectively.

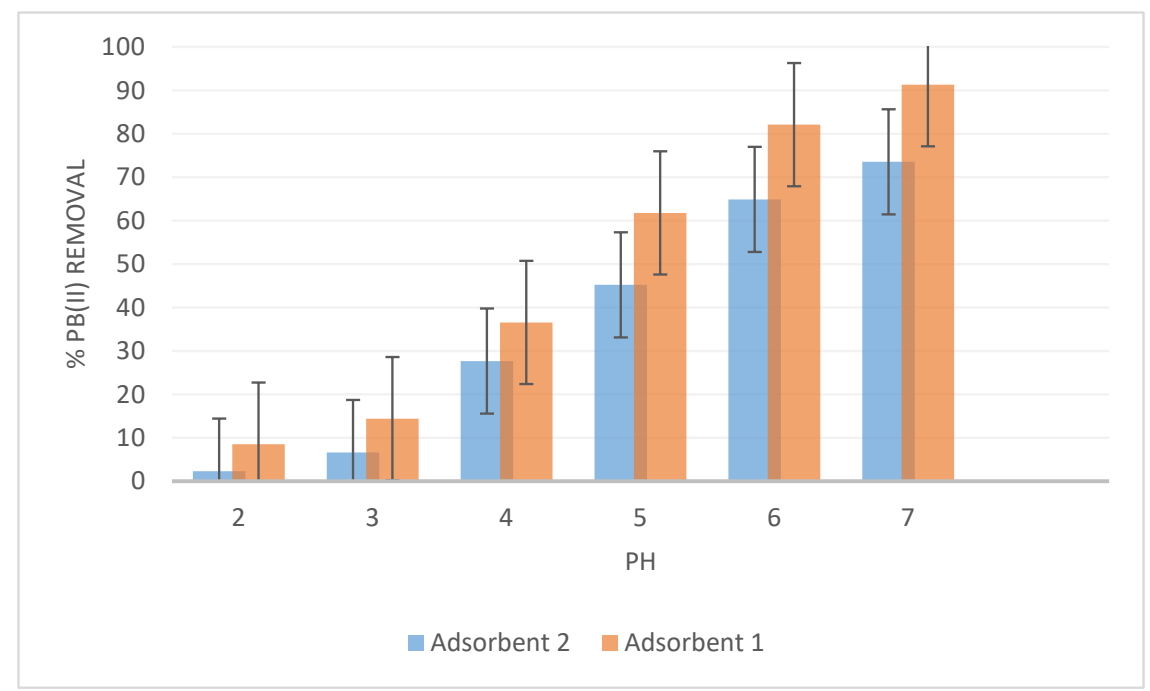

Figure 14. Effects of $\mathrm{pH}$ on the adsorption of $\mathrm{Pb}(\mathrm{II})$ (mean \pm RSD) by adsorbent $\mathbf{1}$ and adsorbent 2. (Experimental conditions: $\mathrm{C}_{\mathrm{o}}=25.52 \mathrm{mg} / \mathrm{L}$, dosage $=0.01 \mathrm{~g}$ per $50 \mathrm{~mL}$, shaking time $2 \mathrm{~h}$, mixing rate $=$ $\left.300 \mathrm{rpm} ; \mathrm{T}=25^{\circ} \mathrm{C}\right)$. Each $\mathrm{pH}$ measurement was done in triplicate. 
From the plot in Figure 14, it can be observed that the $\mathrm{Pb}$ (II) ion uptake sharply increased from $\mathrm{pH} 2.0$ to 7.0. At low $\mathrm{pH}$ values, the interaction of $\mathrm{Pb}(\mathrm{II})$ with adsorbents $\mathbf{1}$ and $\mathbf{2}$ decreases because the surfaces of the adsorbents were fully covered by hydronium $\left(\mathrm{H}_{3} \mathrm{O}^{+}\right)$ions, resulting in minimum adsorption. As $\mathrm{pH}$ increased, the interaction of $\mathrm{Pb}(\mathrm{II})$ with adsorbents $\mathbf{1}$ and $\mathbf{2}$ increased, and the adsorption also increased. Hence, the optimum $\mathrm{pH}$ for the maximum sorption of $\mathrm{Pb}(\mathrm{II})$ was $\mathrm{pH}=7.0$. Above a $\mathrm{pH}$ of 7.0, we observed precipitation of $\mathrm{Pb}(\mathrm{II})$ ions in the form of $\mathrm{Pb}(\mathrm{OH})_{2}$ in a control sample (without adsorbents).

\subsubsection{Effect of Contact Time and Kinetics for the Adsorption of $\mathrm{Pb}(\mathrm{II})$ by Adsorbents $\mathbf{1}$ and $\mathbf{2}$}

The kinetics of $\mathrm{Pb}(\mathrm{II})$ removal were determined in order to understand the adsorption behavior of adsorbents $\mathbf{1}$ and $\mathbf{2}$. Figure 15 illustrates the $\mathrm{Pb}(\mathrm{II})$ ions adsorption on adsorbents $\mathbf{1}$ and $\mathbf{2}$ as a function of contact time (0-340 min). As can be seen from Figure 15, the rate of adsorption of $\mathrm{Pb}$ (II) ions was fairly rapid in the initial stages (in the first $50 \mathrm{~min}$ ). After $60 \mathrm{~min}$, the rate of adsorption slowed down as time progressed and reached a constant value around $60 \mathrm{~min}$ (equilibrium time). The initial rapid adsorption rate before $50 \mathrm{~min}$ could be explained by the fact that at the beginning of the adsorption process, the sites for adsorption were available and open for $\mathrm{Pb}(\mathrm{II})$ ions leading to a higher adsorption rate. As time progressed to greater than $60 \mathrm{~min}$, the adsorption of $\mathrm{Pb}$ (II) ions slowed down because all binding sites were occupied by $\mathrm{Pb}(\mathrm{II})$ ions.



Figure 15. Kinetic adsorption of $\mathrm{Pb}$ (II) on adsorbent $\mathbf{1}$ (a) and adsorbent $\mathbf{2}$ (b) as a function of contact time $(\mathrm{pH} 6.5 \pm 0.2$, initial metal concentration $=20 \mathrm{mg} / \mathrm{L}$, dosage $=50 \mathrm{mg} / 50 \mathrm{~mL}$, mixing rate $=50 \mathrm{rpm}$, $\left.\mathrm{T}=25^{\circ} \mathrm{C}\right)$.

\subsubsection{Adsorption Kinetics for the Adsorption of $\mathrm{Pb}(\mathrm{II})$ by Adsorbents 1 and $\mathbf{2}$}

The dynamics of the adsorption by the adsorbents $\mathbf{1}$ and $\mathbf{2}$ were evaluated using the Lagergren's pseudo-first-order and the McKay and Ho's pseudo-second-order models as defined in Equations (3) and (4), respectively [41,42]:

$$
\log \left(q_{e}-q_{t}\right)=-K_{1} t / 2.303+\log \left(q_{e}\right)
$$




$$
t / q_{t}=1 / K_{2} q e^{2}+t / q_{e}
$$

where $\mathrm{q}_{e}$ is the adsorption capacity $\left(\mathrm{mg} \mathrm{g}^{-1}\right)$ at equilibrium, $\mathrm{q}_{t}$ is the adsorption capacity $\left(\mathrm{mg} \mathrm{g}^{-1}\right)$ at any time $t, k_{1}$ is the rate constants of first-order sorption $\left(\mathrm{min}^{-1}\right)$, and $\mathrm{k}_{2}\left(\mathrm{~g} \mathrm{mg}^{-1} \mathrm{~min}^{-1}\right)$ is the rate constant for the pseudo-second-order adsorption.

Figure 16 shows the linear plot of $t / q_{t}$ versus $t$ for the Lagergren's pseudo-second-order model for the adsorption of $\mathrm{Pb}$ (II) for adsorbents 1 and 2, respectively. The equilibrium rate constants of the pseudo-second-order model $\left(\mathrm{k}_{2}\right)$ were $1.23 \times 10^{-4}$ and $1.03 \times 10^{-3} \mathrm{~g} \mathrm{mg}^{-1} \mathrm{~min}^{-1}$ for $\mathrm{Pb}$ (II) for adsorbents 1 and 2, respectively (Table 4). The pseudo-second-order model (Equation (4)) fit the experimental data very well with a correlation coefficient $\left(R^{2}\right)$ of 0.99 , which was close to unity as shown in Table 4 and Figure 16. On the other hand, our calculations demonstrated that the resulting experimental data were not fitted to the pseudo-first-order model. Therefore, the adsorption kinetics of $\mathrm{Pb}$ (II) ions on the three adsorbents showed that the $\mathrm{Pb}$ (II) adsorption followed a second-order reaction. Moreover, the experimental values of qe (Exp.) for both adsorbents were very close to the calculated values qe (Cal.) measured from the pseudo-second-order equation.
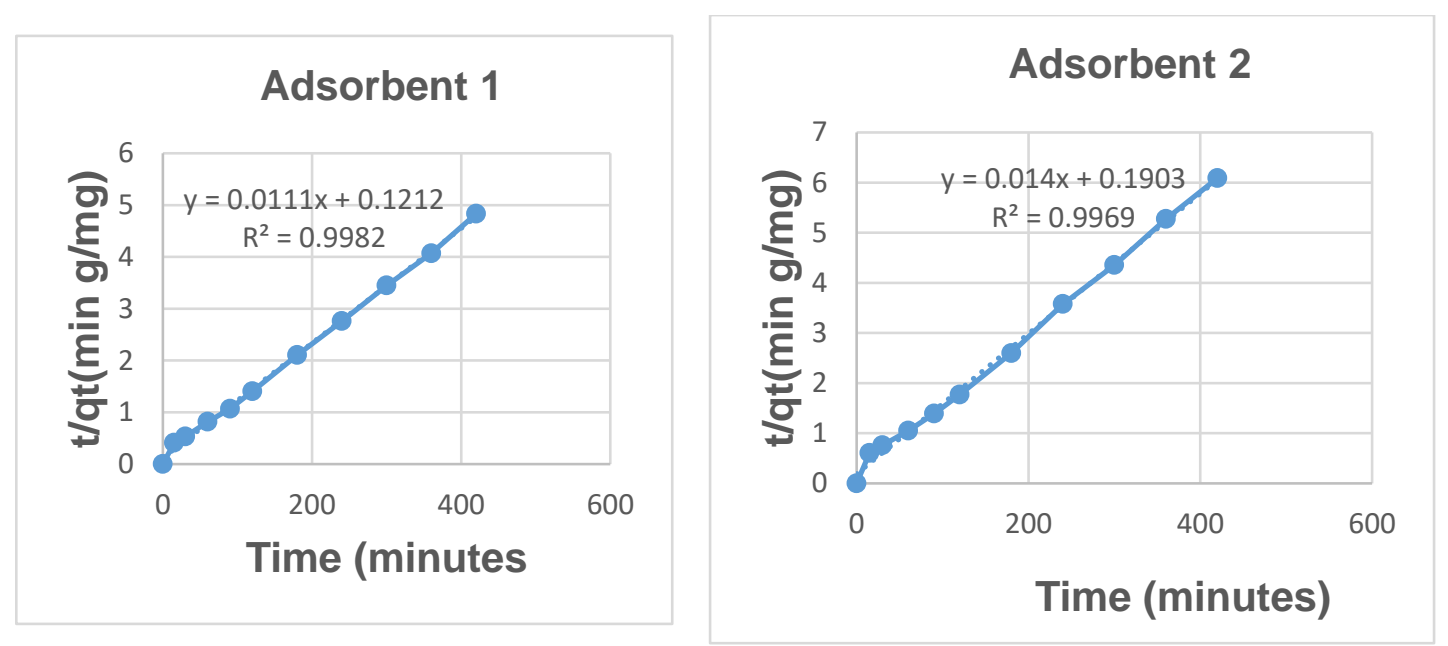

Figure 16. Lagergren pseudo-second-order kinetics adsorption for $\mathrm{Pb}$ (II) onto adsorbents $\mathbf{1}$ and 2 (Experimental conditions: $\mathrm{pH} 6.5 \pm 0.2$, initial metal concentration $=20 \mathrm{mg} / \mathrm{L}$, dosage $=50 \mathrm{mg} / 50 \mathrm{~mL}$, mixing rate $=50 \mathrm{rpm}, \mathrm{T}=25^{\circ} \mathrm{C}$ ).

Table 4. Coefficients of sorption kinetics (Lagergren's pseudo-second-order model) for $\mathrm{Pb}$ (II) removal by adsorbents 1 and 2 and their correlation coefficient $\left(R^{2}\right)$. (Experimental conditions: pH $6.5 \pm 0.2$, initial metal concentration $=20 \mathrm{mg} / \mathrm{L}, 50 \mathrm{mg} / 50 \mathrm{~mL}$, mixing rate $=50 \mathrm{rpm}, \mathrm{T}=25^{\circ} \mathrm{C}$ ).

\begin{tabular}{ccc}
\hline Parameters & Adsorbent 1 & Adsorbent 2 \\
\hline Calculated equilb. uptake qe $(\mathrm{mg} / \mathrm{g})$ & 90.09 & 71.43 \\
\hline $\mathrm{K}_{2}\left(\mathrm{~g} \mathrm{mg}^{-1} \mathrm{~min}^{-1}\right)$ & $1.23 \times 10^{-4}$ & $1.03 \times 10^{-3}$ \\
\hline $\mathrm{R}^{2}$ & 0.9982 & 0.9969 \\
\hline
\end{tabular}

Furthermore, the effect of temperature on the adsorption behavior for $\mathrm{Pb}$ (II) ions was also investigated. The effect of temperature on $\mathrm{Pb}$ (II) ions adsorption by adsorbents $\mathbf{1}$ and $\mathbf{2}$ is shown in Figure 17. The removal of $\mathrm{Pb}$ (II) ions by both adsorbents increased slightly with increasing solution temperature from 25 to $50^{\circ} \mathrm{C}$. This result suggested that the adsorption mechanism associated with $\mathrm{Pb}$ (II) ions on both adsorbents involved a temperature-dependent process to some extent. The adsorbent's weak sensitivity to temperature is essential to practical applications, thereby enabling both synthesized adsorbents to be potentially applied to the practical treatment of $\mathrm{Pb}(\mathrm{II})$ ions at room temperature. 


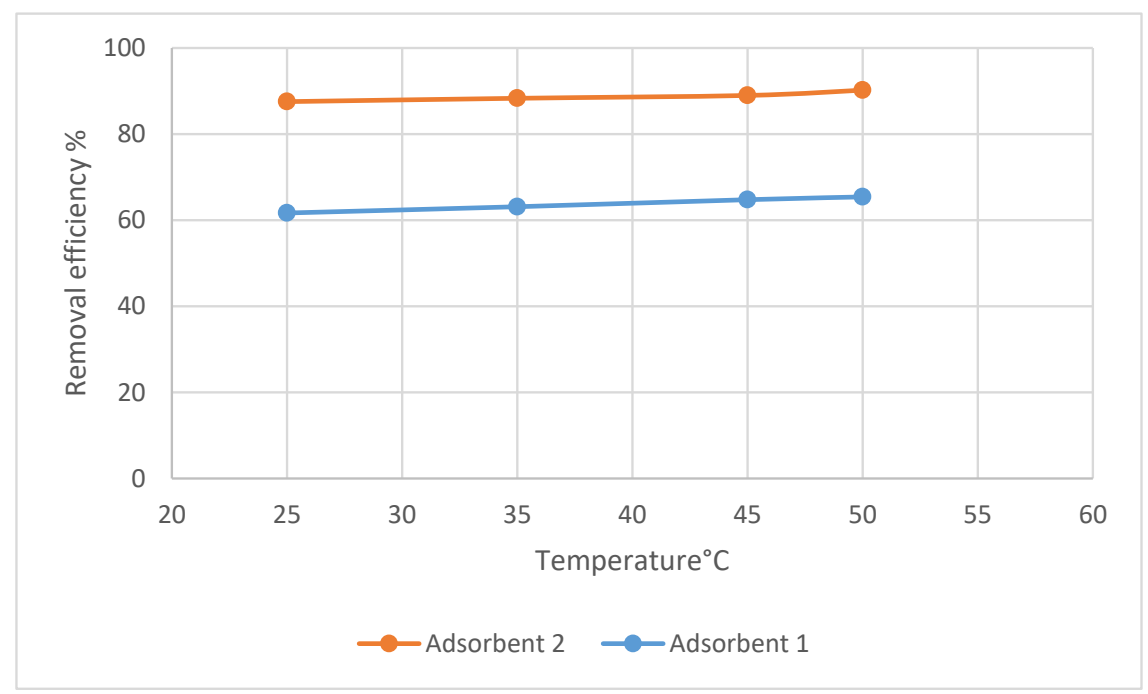

Figure 17. Effect of the temperature on $\mathrm{Pb}$ (II) ion adsorbtion (mean $\pm \mathrm{RSD}$ ) on adsorbent $\mathbf{1}$ and adsorbent 2. ( $\mathrm{pH} 6.5 \pm 0.2$, initial metal concentration $=20 \mathrm{mg} / \mathrm{L} \mathrm{Pb}(\mathrm{II})$, dosage $=50 \mathrm{mg} / 50 \mathrm{~mL}$, at different temperatures for $60 \mathrm{~min}$ ). Each measurement has been done in triplicate.

\subsubsection{Adsorption Isotherms}

The adsorption isotherms were used to determine the affinity of adsorbents $\mathbf{1}$ and $\mathbf{2}$ to $\mathrm{Pb}$ (II) ions. The amount of $\mathrm{Pb}$ (II) ion per gram of adsorbent $\left(q_{e}\right)$ was defined as shown in Equation (1) above. The sorption of $\mathrm{Pb}$ (II) into adsorbents 1 and 2 was described by Langmuir [43,44] and Freundlich [45] models:

- $\quad$ The Langmuir Isotherm Model [43]

$$
\mathrm{q}_{\mathrm{e}}=\mathrm{q}_{\mathrm{m}} \mathrm{K}_{\mathrm{L}} \mathrm{C}_{\mathrm{e}} / 1+\mathrm{K}_{\mathrm{L}} \mathrm{C}_{\mathrm{e}}
$$

where $q_{e}$ is the is the lead concentration adsorbed per specific amount of adsorbent ( $\left.\mathrm{mg} \mathrm{g}^{-1}\right), C_{e}$ is the equilibrium concentration of $\mathrm{Pb}(\mathrm{II})$ expressed in $\mathrm{mg} \mathrm{L}^{-1}$, and $\mathrm{q}_{\mathrm{m}}$ is the maximum amount of lead ions required to form a monolayer $\left(\mathrm{mg} \mathrm{g}^{-1}\right)$. The Langmuir equation can be rearranged to a linear form (Equation (6)) for the convenience of plotting and determination of the Langmuir constant $\left(\mathrm{K}_{\mathrm{L}}\right.$, the first coefficient related to the energy of adsorption) as below. The values of $\mathrm{q}_{\mathrm{m}}$ and $K_{L}$ can be determined from the linear plot of $1 / C_{e}$ versus $1 / q_{e}$ :

$$
1 / q_{e}=1 / q_{m}+1 / K_{L} q m \times 1 / C_{e}
$$

The dimensionless equilibrium parameter or separation factor $\left(R_{L}\right)$ could be expressed as in the following equation [44]:

$$
R_{L}=1 / 1+K_{L} C_{0}
$$

where $C_{0}$ is the initial concentration of the lead ion, and $K_{L}$ is the Langmuir constant. The value of $R_{L}$ is between 0 and 1 for favourable adsorption, while $R_{L}>1$ represents unfavorable adsorption, and $R_{L}=1$ represents linear adsorption. The adsorption process is irreversible if $R_{L}=0$.

- $\quad$ The Freundlich Isotherm Model [45]

$$
\begin{gathered}
q_{e}=K_{F} C_{e}^{1 / n} \\
\log q_{\mathrm{e}}=\log \mathrm{K}_{\mathrm{F}}+(1 / \mathrm{n}) \log \mathrm{C}_{\mathrm{e}}
\end{gathered}
$$

where, $q_{e}$ is the equilibrium uptake capacity $\left(\mathrm{mg} \mathrm{g}^{-1}\right)$ and $C_{e}$ is the equilibrium concentration of $\mathrm{Pb}(\mathrm{II})$ ) expressed in $\mathrm{mg} \mathrm{L}^{-1} \cdot \mathrm{k}_{\mathrm{F}}$ is the first coefficient related to the energy of adsorption, and $\mathrm{n}$ is a coefficient. Both constants $\mathrm{k}_{\mathrm{F}}$ and $\mathrm{n}$ can be calculated from the plot of $\log q_{e} \mathrm{vs.} \log \mathrm{Ce}$. 
* The coefficients were calculated from linearized forms of sorption isotherms models Equations (6) and (9).

\subsubsection{Linear Fitting of the Isotherm Models}

Linear fitting of the Langmuir and Freundlich isotherm models is shown in Figures 18 and 19 respectively; the corresponding parameters of sorption isotherm models calculated are illustrated in Table 5. From the results shown in Table 5, the adsorption process of $\mathrm{Pb}$ (II) on both adsorbents can be described by the linear form of the Langmuir Isotherm Model, which produced higher $\mathrm{R}^{2}$ values of 0.959 and 0.983 for $\mathrm{Pb}(\mathrm{II})$ onto adsorbents 1 and 2, respectively, compared to the Freundlich isotherm model, which produced low $\mathrm{R}^{2}$ values of 0.902 and 0.871 for $\mathrm{Pb}$ (II) onto adsorbents 1 and 2 respectively. Therefore, the adsorption isotherms for both adsorbents fitted well with the Langmuir model more than with Freundlich model; hence, the sorption process of $\mathrm{Pb}$ (II) ions involved in both adsorbents occurred by chemical complexation (chemisorption). The separation factor $\mathrm{R}_{L}$ (Equation (7)) was found to be between 0 and 1 (Table 5) indicating a favorable adsorption process [44].
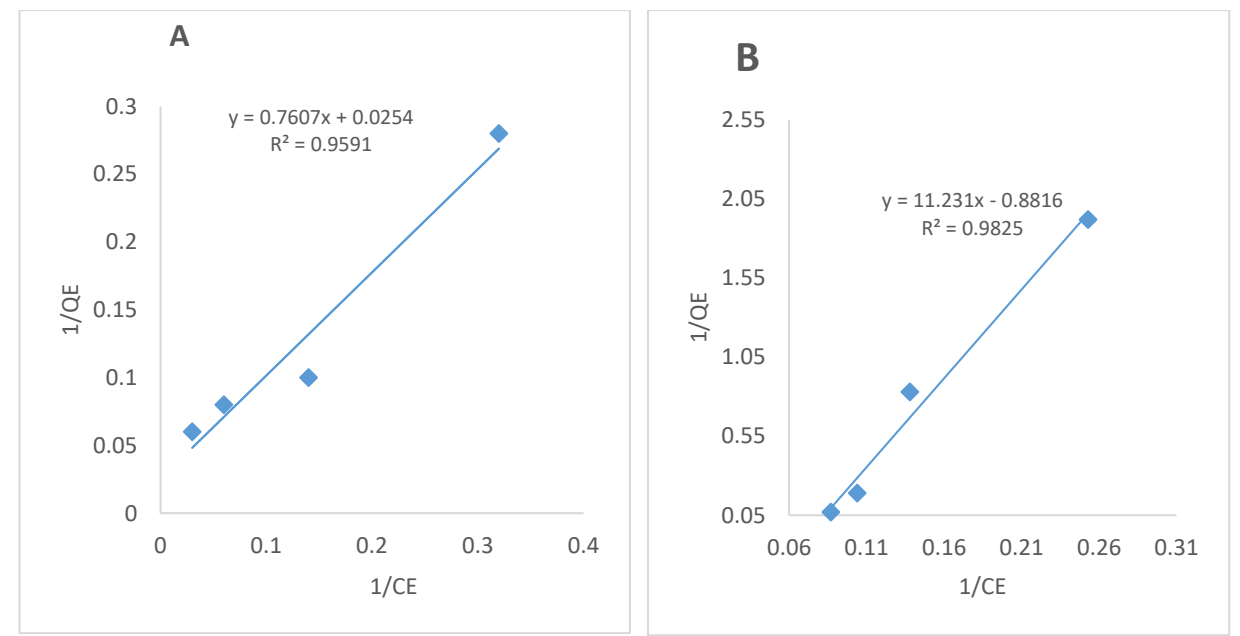

Figure 18. The Langmuir Isotherm Model adsorption for $\mathrm{Pb}(\mathrm{II})$ onto (A) adsorbent $\mathbf{1}$ and (B) adsorbent 2. (Experimental conditions: dosage $=0.015 \mathrm{~g}$ (adsorbent 1) and 0.1 (adsorbent 2 ) per $50 \mathrm{~mL} ; \mathrm{T}=25 \pm$ $1^{\circ} \mathrm{C}$; contact time $=60 \mathrm{~min} . ; \mathrm{pH}=6.5 \pm$ for $\mathrm{Pb}(\mathrm{II})$.

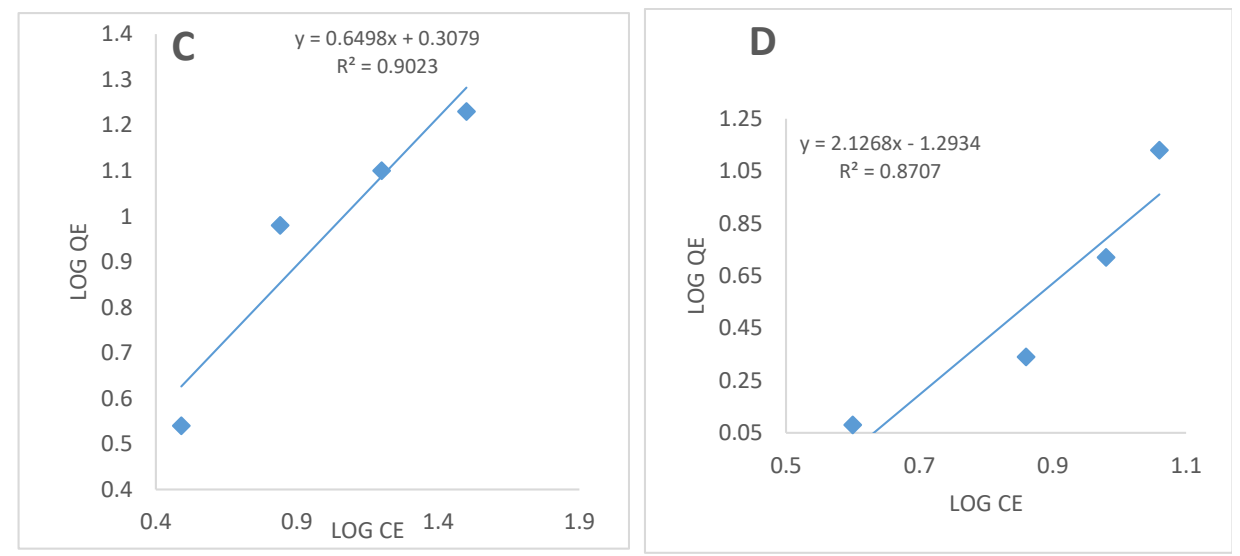

Figure 19. The Freundlich Isotherm Model adsorption for $\mathrm{Pb}$ (II) onto (C) adsorbent $\mathbf{1}$ and (D) adsorbent 2. (Experimental conditions: dosage $=0.015 \mathrm{~g}$ (adsorbent 1 ) and 0.1 (adsorbent 2 ) per $50 \mathrm{~mL} ; \mathrm{T}=25 \pm$ $1{ }^{\circ} \mathrm{C}$; contact time $=60 \mathrm{~min}$; $\mathrm{pH}=6.5 \pm$ for $\mathrm{Pb}(\mathrm{II})$. 
Table 5. Coefficients of two different sorption isotherm models for $\mathrm{Pb}$ (II) removal by adsorbents $\mathbf{1}$ and 2 and their correlation coefficient $\left(R^{2}\right)$. (Experimental conditions: dosage $=0.015 \mathrm{~g}$ (adsorbent $\mathbf{1}$ ) and 0.1 (adsorbent 2) per $50 \mathrm{~mL} ; \mathrm{T}=25 \pm 1{ }^{\circ} \mathrm{C}$; contact time $=60 \mathrm{~min}$.; $\mathrm{pH}=6.5 \pm 0.2$ for $\mathrm{Pb}(\mathrm{II})$.

\begin{tabular}{cccccccc}
\hline \multirow{2}{*}{ Adsorbent } & \multicolumn{7}{c}{ Langmuir Isotherm } \\
\cline { 2 - 8 } & $\mathbf{q m}(\mathbf{m g} / \mathbf{g})$ & $\mathbf{K ~ ( L / m g ) ~}$ & $\mathbf{R L}$ & $\mathbf{R 2}$ & $\mathbf{K F}$ & $\mathbf{1 / n}$ & $\mathbf{R 2}$ \\
\hline & 39.37 & 0.0333 & 0.601 & 0.956 & 2.032 & 1.54 & 0.902 \\
$\mathbf{1}$ & 1.134 & 0.079 & 0.717 & 0.983 & 0.051 & 0.470 & 0.871 \\
\hline
\end{tabular}

a. The Langmuir Isotherm Model

b. The Freundlich Isotherm Model

\subsubsection{Complexation of $\mathrm{Pb}(\mathrm{II})$ by Adsorbent 1}

Adsorbent 1 showed adsorption of $\mathrm{Pb}$ (II) ions due to the presence of Schiff base functionality (azomethine $(\mathrm{C}=\mathrm{N})$, carboxylate oxygen, and active thiol and silanol groups on the surface), whereas adsorbent 2 adsorbs $\mathrm{Pb}(\mathrm{II})$ ions due to the presence of active thiol and silanol groups only on the surface. Adsorbent 1 showed better adsorption of $\mathrm{Pb}(\mathrm{II})$ ions, which may be attributed to the presence of potentially good coordinating Schiff base sites and active carboxylate oxygen, in addition to thiol and hydroxyl groups. The shift of asymmetric stretching vibration of vas $\left(\mathrm{COO}^{-}\right)$of adsorbent 1 at 1665 $\mathrm{cm}^{-1}$ to a lower wave number $1642 \mathrm{~cm}^{-1}$ and the disappearance of the thiol S-H peak at $2556 \mathrm{~cm}^{-1}$ after $\mathrm{Pb}$ (II) ion was loaded confirmed the chemical complexation of $\mathrm{Pb}$ (II) by adsorbent $\mathbf{1}$ (Figure $2 \mathrm{~b}$ ). The FTIR results (Figure $2 \mathrm{~b}$ ) support the structures proposed for $\mathrm{Pb}$ (II) ion interaction with adsorbent 1 (complex) during the adsorption process [46]. The $\mathrm{Pb}$ (II) ions interaction with adsorbent $\mathbf{1}$ is shown in Figure 20 below.



Figure 20. $\mathrm{Pb}(\mathrm{II})$ ion adsorbent 1 complex formation. 


\section{Conclusions}

In this study, novel silica functionalized with Schiff-base (adsorbent 1) and propyl-thiol (adsorbent 2) were successfully prepared. Direct hydrolysis of 3-(triethoxysilyl) propane-1-thiol gave adsorbent 2, and mixing 3-(triethoxysilyl) propane-1-thiol with a Schiff base produced a good yield of adsorbent 1. The new materials were well characterized by FTIR, SEM, XRD, nitrogen adsorption-desorption isotherms, BET surface area, BJH pore sizes, TGA, and ${ }^{1} \mathrm{H}$ and ${ }^{13} \mathrm{C}$ NMR spectra. The newly synthesized adsorbents $\mathbf{1}$ and $\mathbf{2}$ displayed good thermal stability and adsorption capacity from aqueous solutions towards $\mathrm{Pb}$ (II) ions. The higher removal efficiency for $\mathrm{Pb}$ (II) by adsorbent 1 could be attributed to the higher surface area $\left(20.1656 \mathrm{~m}^{2} / \mathrm{g}\right)$, which facilitated the interaction of free $\mathrm{Pb}$ (II) ions present in solution with the surface of adsorbent 1 . The adsorption isotherms of $\mathrm{Pb}$ (II) fitted well with the Langmuir Isotherm Model, indicating that the adsorption mechanism followed Langmuir monolayer adsorption, and the adsorption kinetics of $\mathrm{Pb}$ (II) followed the pseudo-second-order kinetic models. In addition, the newly synthesized materials were proven to be cost-effective adsorbents and could be used for the selective extraction of $\mathrm{Pb}$ (II) from contaminated water. Overall, our studies suggested that adsorbent 1 could be considered as a good candidate for removing $\mathrm{Pb}(\mathrm{II})$ from aqueous solutions.

Supplementary Materials: The following are available online at http://www.mdpi.com/2227-9717/8/2/246/s1, Figure S1. ${ }^{1} \mathrm{H}$-nuclear magnetic resonance (NMR) absorption spectrum of the Schiff base. Figure S2. ${ }^{13} \mathrm{C}$ NMR spectra of the Schiff base. Figure S3. Thermogravimetric (TGA) curves of the Schiff base.

Author Contributions: Methodology: M.O.A., A.S., and M.M.; Software: M.O.A., A.S.; Writing-Original Draft Preparation: A.S.; Writing-Review \& Editing: M.O.A.; Project Administration: M.O.A. All authors have read and agreed to the published version of the manuscript.

Funding: This research received no external funding.

Conflicts of Interest: The authors declare no conflicts of interest.

\section{References}

1. Huuha, T.S.; Kurniawan, T.A.; Sillanpaa, M.E.T. Removal of silicon from pulping whitewater using integrated treatment of chemical precipitation and evaporation. Chem. Eng. J. 2010, 158, 584-592. [CrossRef]

2. El-Nasser, A.; Parish, R. Solid polysiloxane ligands containing glycine- or iminodiacetate-groups: Synthesis and application to binding and separation of metal ions. J. Chem. Soc. Dalton Trans. 1999, 19, 3463-3466. [CrossRef]

3. El-Nahhal, I.M.; El-Shetary, B.A.; Salib, K.A.R.; El-Ashgar, N.M.; El-Hashash, A.M. Uptake of divalent metal ions $\left(\mathrm{Cu}^{2+}, \mathrm{Ni}^{2+}\right.$, and $\left.\mathrm{Co}^{2+}\right)$ by polysiloxane immobilized triamine-thiol- and thiocyanate ligand system. Anal. Lett. 2001, 34, 2189-2202. [CrossRef]

4. Najafi, M.; Rostamian, R.; Rafati, A.A. Chemically modified silica gel with thiol group as an adsorbent for retention of some toxic soft metal ions from water and industrial effluent. Chem. Eng. J. 2011, 168, 426-432. [CrossRef]

5. Esalah, O.; Weber, M.; Vera, J. Removal of lead, cadmium and zinc from aqueous solutions by precipitation with sodium Di-(n-octyl) phosphinate. Can. J. Chem. Eng. 2000, 78, 948-954. [CrossRef]

6. Lertlapwasin, R.; Bhawawet, N.; Imyim, A.; Fuangswasdi, S. Ionic liquid extraction of heavy metal ions by 2-aminothiophenol in 1-butyl-3-methylimidazolium hexafluorophosphate and their association constants. Sep. Purif. Technol. 2010, 72, 70-76. [CrossRef]

7. Emamjomeh, M.M.; Sivakumar, M. Review of pollutants removed by electrocoagulation and electrocoagulation/flotation processes. J. Environ. Manag. 2009, 90, 1663-1679. [CrossRef]

8. Mahmoud, A.; Hoadley, A. An evaluation of a hybrid ion exchange electrodialysis process in the recovery of heavy metals from simulated dilute industrial wastewater. Water Res. 2012, 46, 3364-3376. [CrossRef]

9. Yurloval, L.; Kryvoruchko, A.; Kornilovich, B. Removal of Ni (II) ions from wastewater by micellar-enhanced ultrafiltration. Desalination 2002, 144, 255-260. [CrossRef]

10. Greenlee, L.; Lawler, D.; Freeman, B.; Marrot, B.; Moulin, P. Reverse Osmosis Desalination: Water Sources, Technology and Today's Challenges. Water Res. 2009, 43, 2317-2348. [CrossRef]

11. Benit, Y.; Ruiz, M. Reverse osmosis applied to metal finishing wastewater. Desalination 2002, 142, $229-234$. [CrossRef] 
12. Rubio, J.; Souza, M.; Smith, R.W. Overview of flotation as a wastewater treatment technique. Miner. Eng. 2002, 15, 139-155. [CrossRef]

13. Ghurye, G.; Clifford, D.; Tripp, A. Iron coagulation and direct microfiltration to remove arsenic from groundwater. Am. Water Work. Assoc. 2004, 96, 143-152. [CrossRef]

14. Wang, L.; Wu, X.; Xu, W.; Huang, X.; Liu, J.H. Stable Organic-Inorganic Hybrid of Polyaniline/ $\alpha$-Zirconium Phosphate for Efficient Removal of Organic Pollutants in Water Environment. Appl. Mater. Interfaces 2012, 4, 2686-2692. [CrossRef]

15. Gao, B.; Gao, Y.; Li, Y. Preparation and chelation adsorption property of composite chelating material poly (amidoxime) $/ \mathrm{SiO}_{2}$ towards heavy metal ions. Chem. Eng. J. 2010, 158, 542-549. [CrossRef]

16. Zaitseva, N.; Zaitsev, V.; Walcarius, A. Chromium (VI) removal via reduction-sorption on bi-functional silica adsorbents. J. Hazard. Mater. 2013, 250, 454-461. [CrossRef]

17. Simsek, E.; Duranoglu, D.; Beker, U. Heavy Metal Adsorption by Magnetic Hybrid-Sorbent: An Experimental and Theoretical Approach. Sep. Sci. Technol. 2012, 47, 1334-1340. [CrossRef]

18. Suchithra, P.; Vazhayal, L.; Mohamed, A.; Ananthakumar, S. Mesoporous organic-inorganic hybrid aerogels through ultrasonic assisted sol-gel intercalation of silica-PEG in bentonite for effective removal of dyes, volatile organic pollutants and petroleum products from aqueous solution. Chem. Eng. J. 2012, 200, 589-600. [CrossRef]

19. Repo, E.; Warchoł, J.; Bhatnagar, A.; Sillanpää, M. Heavy metals adsorption by novel EDTA-modified chitosan-silica hybrid materials. J. Colloid Interface Sci. 2011, 358, 261-267. [CrossRef]

20. Ge, P.; Li, F.; Zhang, B. Synthesis of modified mesoporous materials and comparative studies of removal of heavy metal from aqueous solutions. Pollut. J. Environ. Stud. 2010, 19, 301-308.

21. Pang, Y.; Zeng, G.; Tang, L.; Zhang, Y.; Liu, Y.; Lei, X.; Li, Z.; Zhang, J.; Xie, G. PEI-grafted magnetic porous powder for highly effective adsorption of heavy metal ions. Desalination 2011, 281, 278-284. [CrossRef]

22. Wang, L.; Zhang, J.; Wang, A. Fast removal of methylene blue from aqueous solution by adsorption onto chitosan-g-poly (acrylic acid)/attapulgite composite. Desalination 2011, 266, 33-39. [CrossRef]

23. Mercier, L.; Pinnavaia, T. Heavy Metal Ion Adsorbents Formed by the Grafting of a Thiol Functionality to Mesoporous Silica Molecular Sieves: Factors Affecting Hg (II) Uptake. Environ. Sci. Technol. 1998, 32, 2749-2754. [CrossRef]

24. Sanchez, C.; Julián, B.; Belleville, P.; Popall, M. Applications of hybrid organic-inorganic nanocomposites. J. Mater. Chem. 2005, 15, 3559-3592. [CrossRef]

25. Yanagisawa, T.; Schhimizu, T.; Kuroda, K.; Kato, C. The preparation of alkyltrimethylammonium-kanemite complexes and their conversion to microporous material. Bull. Chem. Soc. 1990, 63, 988-992. [CrossRef]

26. Kubota, Y.; Nishizaki, Y.; Sugi, Y. High Catalytic Activity of as-Synthesized, Ordered Porous Silicate-Quaternary Ammonium Composite for Knoevenagel Condensation. Chem. Lett. 2000, 29, 998-999. [CrossRef]

27. Wu, J.; Liu, X.; Tolbert, S. High-Pressure Stability in Ordered Mesoporous Silicas: Rigidity and Elasticity through Nanometer Scale Arches. J. Phys. Chem. 2000, 104, 11837-11841. [CrossRef]

28. Wu, J.; Abu-Omar, M.; Tolbert, S. Fluorescent Probes of the Molecular Environment within Mesostructured Silica/Surfactant Composites under High Pressure. Nanoletters 2001, 1, 27-31. [CrossRef]

29. Diaz, J.; Balkus, J.; Bedioui, F.; Kurshev, V.; Kevan, L. Synthesis and Charact-erization of Cobalt-Complex Functionalized MCM-41. Chem. Mater. 1997, 9, 61-67. [CrossRef]

30. Liu, J.; Song, L.; Shao, G. Novel Zwitterionic Inorganic-Organic Hybrids: Kinetic and Equilibrium Model Studies on $\mathrm{Pb}^{2+}$ Removal from Aqueous Solution. J. Chem. Eng. Data 2011, 56, 2119-2127. [CrossRef]

31. Pavan, F.; Costa, T.; Benvenutti, E. Adsorption of $\mathrm{CoCl}_{2}, \mathrm{ZnCl}_{2}$ and $\mathrm{CdCl}_{2}$ on aniline/silica hybrid material obtained by sol-gel method. Colloids Surf. A Physicochem. Eng. Asp. 2003, 226, 95-100. [CrossRef]

32. Radi, S.; Tighadouini, S.; Bacquet, M.; Degoutin, S.; Cazier, F.; Zaghrioui, M.; Mabkhot, Y.N. Organically Modified Silica with Pyrazole-3-carbaldehyde as a New Sorbent for Solid-Liquid Extraction of Heavy Metals. Molecules 2014, 19, 247-262. [CrossRef]

33. Qu, R.; Zhang, Y.; Qu, W.; Sun, C.; Chen, J.; Ping, Y.; Chen, H.; Niu, Y. Mercury adsorption by sulfur- and amidoxime-containing bifunctional silica gel based hybrid materials. Chem. Eng. J. 2013, 219, 51-61. [CrossRef]

34. Anbarasu, G.; Malathy, M.; Karthikeyan, P.; Rajavel, R. Silica functionalized Cu (II) acetylacetonate Schiff base complex: An efficient catalyst for the oxidative condensation reaction of benzyl alcohol with amines. J. Solid State Chem. 2017, 253, 305-312. [CrossRef]

35. Singh, H.; Singh, J.B. Synthesis and Characterization of New Lead (II) and Organotin (IV) Complexes of Schiff Bases Derived from Histidine and Methionine. Int. J. Inorg. Chem. 2012, 2012. [CrossRef] 
36. Sandhu, G.K.; Verma, S.P. Triorganotin (IV) derivatives of five membered heterocyclic 2-carboxylic acids. Polyhedron 1987, 6, 587-592. [CrossRef]

37. Miao, J.; Qian, J.; Wang, X.; Zhang, Y.; Yang, H.; He, P. Synthesis and characterization of ordered mesoporous silica by using polystyrene microemulsion as templates. Mater. Lett. 2009, 63, 989-990. [CrossRef]

38. Helloa, K.; Ibrahimb, A.; Jawad, K.; Shneineb, J. Simple method for functionalization of silica with alkyl silane and organic ligand. South Afr. J. Chem. Eng. 2018, 25, 159-168. [CrossRef]

39. Naghmeh, D.; Niaz, M.; Mahmood, T. Preparation and Characterization of a Molybdenum (VI) Schiff Base Complex as Magnetic Nanocatalyst for Synthesis of 2-Amino-4H-benzo[h]chromenes. J. Nanostruct. 2016, 6, 312-321. [CrossRef]

40. Xue, X.; Li, F. Removal of $\mathrm{Cu}$ (II) from aqueous solution by adsorption onto functionalized SBA-16 mesoporous silica. Microporous Mesoporous Mater. 2008, 116, 116-122. [CrossRef]

41. Ramesh, A.; Hasegawa, H.; Maki, T.; Ueda, K. Adsorption of inorganic and organic arsenic from aqueous solutions by polymeric Al/Fe modified montmorillonite. Sep. Purif. Technol. 2007, 56, 90-100. [CrossRef]

42. Ho, Y.; McKay, G. Pseudo-second order model for sorption processes. Process Biochem. 1999, 34, 451-465. [CrossRef]

43. Langmuir, I. The adsorption of gases on plain surface of glass, mica and platinum. J. Am. Chem. Soc. 1918, 40, 1361-1368. [CrossRef]

44. Weber, T.W.; Chakravorti, R.K. Pore and solid diffusion models for fixed bed adsorbers. AIChE J. 1974, 20, 228-238. [CrossRef]

45. Freundlich, H. Über die adsorption in lösungen. Zeitschrift für Physikalische. Chemie 1907, 57, 385-470. [CrossRef]

46. Karthik, R.; Meenakshi, S. Removal of $\mathrm{Pb}$ (II) and Cd (II) ions from aqueous solution using polyaniline grafted chitosan. Chem. Eng. J. 2015, 263, 168-177. [CrossRef]

(C) 2020 by the authors. Licensee MDPI, Basel, Switzerland. This article is an open access article distributed under the terms and conditions of the Creative Commons Attribution (CC BY) license (http://creativecommons.org/licenses/by/4.0/). 